\title{
SHOULD CENTRAL BANKS BURST BUBBLES? SOME MICROECONOMIC ISSUES
}

\author{
John R. Conlon* \\ Department of Economics \\ University of Mississippi \\ University, MS 38677 \\ jrconlon@olemiss.edu
}

August 11, 2008

\begin{abstract}
Policy towards speculative bubbles is examined in a model of a finite horizon "greater fool" bubble, with rational agents, asymmetric information and short-sales constraints. This model permits the use of standard tools of comparative dynamics and welfare economics to analyze bubble policies.

Government policy is modeled as deflating overpriced assets by revealing information about this overpricing. We assume in this paper that the central bank only deflates assets if they are, in fact, overpriced. However, the central bank is never the only one to know that assets are overpriced.

In this environment, a policy rule of deflating overpriced assets also influences expectations in states of the world where the central bank does nothing. That is, if the central bank is following a bubble-bursting rule, then the market interprets inaction as an implicit endorsement of asset prices, which raises these prices. This can reduce the lemons problem caused by asymmetric information, if prices rise because the policy protects uninformed buyers from "bad sellers" who know assets are overpriced. However, if the central bank only deflates "strong bubbles," where all investors already know the asset is overpriced, then inaction raises prices because bad sellers become more confident, and this tends to make the lemons problem worse.

* The paper benefitted greatly from discussions with Franklin Allen, Mike Belongia, Richard Boylan, Sumali Conlon, Doug Cook, Chris Hanes, Ron Harstad, Guo Kai, Stephen Morris, Roger Myerson, Pat Peavy, Paul Pecorino, Marcin Pesski, Andrew Postlewaite, Bernard Sinclair-Desgagné, Hugo Sonnenschein, George Tolley, Mark Van Boening, Robert Van Ness, Hui-chen Wang, Hugh Wilson, and Andrew Young, and from presentations at Rutgers, HEC Montréal, the Universities of Mississippi, Memphis, Chicago and Missouri, the Second World Congress of the Game Theory Society in Marseille, and the Ninth World Congress of the Econometric Society in London. Support from NSF grant SES 0215631 is also gratefully acknowledged. Remaining errors are mine.
\end{abstract}


Asset prices have fluctuated wildly in recent years, and many have attributed these fluctuations to asset price bubbles (Higgins and Osler, 1997, Shiller, 2000, 2007, Ofek and Richardson, 2003). ${ }^{1} \quad$ There has also been a heated debate about whether central banks should try to deflate these bubbles (Bernanke and Gertler, 1999, 2001, Cecchetti and coauthors, 2000, 2003, Bordo and Jeanne, 2002, Hunter, et al. 2003, Bean, 2004, Mishkin, 2007). During the Internet boom, for example, the Economist (1998) opined that "the Fed made a mistake in not raising interest rates last year to let some air out of the bubble," and again, during the recent housing boom, the Economist (2007) complained that "if the Fed should anticipate the economic consequences of a deflating bubble, why should it not anticipate the consequences of an inflating one?"

The Economist's position seems sensible, assuming the Fed can identify bubbles, since it is presumably a good idea to restore asset prices to reasonable levels. Of course, the Fed may not be able to identify bubbles. However, central bankers also seem to see additional complications in bubble-bursting policy. In particular, they often worry about the effects such policies would have on expectations. For example, in the March 30, 1999 Federal Open Market Committee (FOMC) meeting (p. 66), President Jordan of the Cleveland Fed worried about even being perceived as trying to burst bubbles:

"It is also true, in view of the stock market finally closing above 10,000 yesterday, that a tightening step could easily be interpreted - unfortunately, and in my view wrongly - that we considered that undesirable and we reacted to it. What is troubling about that is that it leads to the implication that we have to wait until growth slows sharply and the stock market drops and then it will be safe to raise rates. [Laughter]"

More specifically, central bankers have worried that, if they pursue antibubble policies, but their policy actions are insufficiently aggressive, then this may only encourage bubbles. For example, in the May 19, 1998 FOMC meeting (pp. 84-85), Alan

1 Of course, there are strong disagreements on whether bubbles even exist. See Kindleberger (2000) and Garber (2000) among many others. 
Greenspan suggested that

"[t]he more interesting question is whether, even if we were to decide we had a bubble and we wanted to let the air out of it, we would be able to do it. ... we have to be very wary of the notion that a small 25 or 50 basis point move could permanently unwind this bubble. Unquestionably, it will do so for a short period of time, but it may then merely set the stage for a further rise that may in fact be highly destabilizing."

As Schlesinger (1999) put it, "if we tried" to burst a bubble "the odds are we would either fail - which would only embolden the partygoers further - or we would have to destroy the dance hall to succeed" (emphasis added). Along the same lines, William White of the Bank for International Settlements suggests that "[e]ach time short rates rise and the bubble continues to expand, ... the market is confirmed in its belief in a 'new era'" (Cecchetti et al., 2000, p. 108).

By a similar logic, if investors are expecting the central bank to move against a bubble, but it does not do so, then this may be taken as an implicit endorsement of asset prices, and so, may drive prices up further. Thus, policy makers may be reluctant to become "arbiter[s] of security speculation or values" (Friedman and Schwartz, 1963, p. 290, quoting the Federal Reserve Board). That is, central bankers may be concerned that, if they adopt a bubble bursting policy rule, then any action - or inaction - will tend to move markets. ${ }^{2}$

Unfortunately, it has been difficult for economic theory to address these issues, since there have been few theoretical models in which to examine the welfare implications of policies towards bubbles. Standard models of rational bubbles use an infinite-horizon framework, where agents hold overpriced assets because they believe

2 In addition, policy makers worry that, in the presence of bubbles, asset prices become fragile, so policy effects are unpredictable. As Mishkin (2007), p. 399-400, explains, "[t]he effect of interest rates on asset-price bubbles is highly uncertain," and raising rates "may cause a bubble to burst more severely ..." Thus "it is heroic to expect the tools of monetary policy to work normally in abnormal conditions." 
these assets will be overpriced forever in expected value. ${ }^{3}$ These models, however, violate market participants' intuition that bubbles eventually burst. ${ }^{4}$ In addition, bubbles generally improve welfare in these models. ${ }^{5}$

For these reasons, most studies of bubble policy simply assume an exogenous gap between the market price of an asset and its fundamental value (Kent and Lowe, 1997, Bernanke and Gertler, 1999, 2001, Cecchetti and coauthors, 2000, 2003, and Dupor, 2005). However, since overpricing is exogenous in these models, it is impossible to capture the effects of policy on expectations and overpricing, discussed above.

These models are therefore vulnerable to the Lucas Critique. Also, since the process driving bubbles is never explicitly modeled in these papers, it is impossible to relate the welfare effects of bubble policy to the market failures that generate bubbles. ${ }^{6}$

This paper therefore analyzes bubble policy using an explicit, fully endogenous model of a bubble. Specifically, we assume a "greater fool" model of asset price bubbles,

3 See Samuelson (1958), Blanchard and Watson (1982), Tirole (1985), Santos and Woodford (1997), or LeRoy (2004).

4 Warren Buffett (2001) describes investors in bubble markets as resembling "Cinderella at the ball. They know that overstaying the festivities ... will eventually bring on pumpkins and mice" but they "all plan to leave just seconds before midnight." Unfortunately, "the clocks have no hands." Similarly, Kindleberger (2000, p. 15) suggests that "the word ... bubble foreshadows the bursting" (emphasis his).

${ }^{5}$ For example, in Samuelson (1958), a bubble in fiat currency makes it possible for people to save for old age. In Tirole (1985), a bubble in an intrinsically useless asset allows people to save without wasting resources overproducing capital. It is unlikely that recent boom-bust cycles in asset prices served either of these functions.

${ }^{6}$ Gai et al. (2004) endogenize their bubble, using the Miller (1977) model of disagreement in the context of short sales constraints. However, they do not do a full welfare analysis of their model. 
where investors hold overpriced assets in hopes of selling them to someone else - a "greater fool" - before asset prices collapse. ${ }^{7}$

Many recent bubble models have a greater fool flavor (Harrison and Kreps, 1978, Scheinkman and Xiong, 2003, Allen and Gorton, 1993, Allen and Gale, 2000, Allen et al., 1993, Conlon, 2004, Abreu and Brunnermeier, 2003, Doblas-Madrid, 2008). Also, greater fool models are consistent with evidence that asset price booms put pressure on brokers' loans (Rappoport and White, 1993, 1994) and put options (Bates, 1991), since these suggest that some agents anticipate a crash. In addition, stocks which are expensive to short have lower expected returns (Jones and Lamont, 2002), which is also consistent with a greater fool dynamic. Finally, Ofek and Richardson (2003), Temin and Voth (2004), Brunnermeier and Nagel (2004) and Dhar and Goetzmann (2005) argue that many traders followed greater fool strategies during the South Sea bubble and the Internet boom.

It is difficult, however, to capture this greater fool dynamic in standard economic models, where all agents are perfectly rational. Fortunately, a major breakthrough in modeling greater-fool bubbles with rational agents was achieved a decade ago by Allen, Morris and Postlewaite (1993). These authors consider a finite horizon model, so any bubbles must eventually burst, consistent with the intuition of market participants. They then use asymmetric information and short sale constraints to model a "strong bubble," where everyone knows that an asset is overpriced. Agents hold an asset they know is overpriced because, with asymmetric information, no one knows whether anyone else also knows the asset is overpriced. Thus, everyone hopes to sell the asset

7 Kindleberger (2000), traces an explicit statement of this theory as far back as 1890 , when the Chicago Tribune editorialized about "men who bought property at prices they knew perfectly well were fictitious, but who ... knew that some still greater fool could be depended on to take the property off their hands and leave them with a profit" (p. 111; see also Chancellor, 2000, p. 95). 
to someone else, yielding a greater fool bubble.

Unfortunately, the Allen et al. example is too complicated to work with easily. Recently, Conlon (2004) simplified the Allen et al. approach, making it more straightforward to analyze issues related to asset price bubbles.

We therefore analyze asset deflation policies in a simplified Allen et al. (1993) greater fool model. Welfare analysis is especially convenient in greater fool models with rational agents since standard tools of welfare economics then apply. In particular, welfare analysis can be based on utility functions which agents themselves maximize. However, while rational bubble models are therefore a natural place to begin, models based on irrationality, such as Scheinkman and Xiong (2003) and Abreu and Brunnermeier (2003), are also important topics of future research. ${ }^{8}$

Our bubble is structured as follows. First, there are several possible states of the world, and agents have incomplete information about which one of these states is the true state. In some states, half the agents are "good sellers," whose asset might be valuable, and half are "buyers." In other states, half are "bad sellers," who know their asset is worthless, and half are buyers. In still other states, all agents are bad sellers.

\footnotetext{
8 Asymmetric information models, such as the one we consider, are especially well suited to study the instabilities of concern to policy makers, discussed above (Allen et al., 2006). In addition, actual investors, even if irrational, are smart enough to analyze and reassess their environments, and such reassessments are clearly central to models of bubbles and crashes. Again, asymmetric information models are ideal for capturing such nontrivial investor information processing and reassessments (see, e.g., Abreu and Brunnermeier, 2003, and Doblas-Madrid, 2008).

As explained in Section 4, the present model can also be reinterpreted to incorporate the overconfidence assumption of Scheinkman and Xiong (2003). The fact that a similar framework can treat models with or without such irrationality is important, since it provides economists who prefer rational models, and those who prefer behavioral models, with a common framework in which to analyze bubbles. This is valuable, since it is clearly still too early in the development of this important field to settle definitively on one model to the exclusion of others.
} 
Buyers are willing to buy because they do not know whether sellers are good or bad. In addition, there are nontrivial gains from trade if the seller is good - due to hedging, say - which compensate for the danger of buying from a bad seller. It is therefore rational for these buyers to risk becoming the "greater fools" that bad sellers hope to sell to. That is, bad sellers create a lemons problem, since they cause buyers to trust good sellers less (Akerlof, 1970), but gains from trade are large enough to at least partially overcome this lemons problem. A strong bubble in the sense of Allen et al. (1993) is then a state of the world in which bad sellers hope they are facing these greater-fool buyers, but they are actually just facing other bad sellers.

In the present model, the only policy tool capable of influencing asset prices is the release of information. This is because the discount rate is fixed (at zero), and the elasticity of demand for assets is infinite, so agents bid prices up to the certainty equivalent of expected future prices, regardless of supply. Open market operations, for example, would have no effect here, beyond the information revealed about central bank beliefs. We therefore simply represent the central bank's policy as the release of this information, and ignore other aspects of central bank policy. ${ }^{9}$

We must then specify what the central bank knows. This paper assumes that the

9 As Stefan Ingves (2007), the governor of the Swedish central bank, explains in the case of Swedish policy, "when we observe long periods of high growth rates in asset prices and debt, growth rates that appear to be unsustainable in the long run, our view is that it is not reasonable to completely ignore" this. "What this view has meant in practice is fairly marginal changes in the timing of our interest rate changes, and substantial public oral and written focus on the issue" (p. 433-34; emphasis added; note also that Sweden's policy is not without its critics: see Mishkin, 2007, p. 397). Allen et al. (2006) and Gai et al. (2004) also consider models where announcements matter. In addition, if information is important, interest rate policy itself may serve largely as a signal of central bank information. Of course, the announcer in the present paper could be some other government agency, such as the SEC or the Treasury, rather than the central bank. 
central bank only believes an asset is overpriced if it really is overpriced. Thus, the central bank is never wrong in believing an asset is overpriced. However, we assume that the central bank only knows an asset is overpriced if some private agents also know this. That is, the central bank is never the only one to know the asset is overpriced.

Within this context, we consider two extreme information structures for the central bank. In the first, the central bank is relatively smart in the sense that it can know an asset is overpriced even if some private agents do not know this. If the central bank then deflates these overpriced assets, we call this a policy of "general deflation of overpriced assets." Note that this is not yet the bursting of an Allen et al. strong bubble, since some agents - buyers, say - may not know the asset is overpriced.

In this case, since the central bank may know more than some buyers, a policy of general deflation of overpriced assets can protect these buyers from bad sellers who know the asset is worthless. This raises the price received by good sellers, who believe the asset may be valuable, and so, reduces the lemons problem.

This extreme case is contrasted to the opposite extreme, i.e., bubble bursting proper. In this case the central bank only knows an asset is overpriced if there is a strong bubble, so all private agents also know the asset is overpriced. That is, the central bank is no better informed about fundamentals than any private agent.

Thus, bubble bursting announcements reveal nothing to private agents about fundamentals. However, the central bank can make information about fundamentals common knowledge. Specifically, since the central bank only knows an asset is overpriced if everyone else does, the central bank's announcement tells bad sellers that all other agents are also bad sellers.

A policy of bursting bubbles therefore protects these bad sellers from each other. Thus, in states of the world where the central bank turns out not to announce a bubble, bad sellers become more confident of selling the asset, exacerbating the lemons problem 
faced by good sellers. This negative effect can outweigh the positive effect of preventing bad sellers from wasting resources in bubble states.

Thus, while bubbles may be a symptom of asymmetric information, which is a bad thing, eliminating this particular symptom may make the underlying problem worse.

Note that the "general deflation" case above may resemble the Cecchetti et al. view, since the central bank knows relatively more. On the other hand, the "bubble bursting" case may more closely resemble the Bernanke and Gertler view, since the central bank knows very little. Thus, these extreme cases should illuminate the major issues which would also arise in less extreme intermediate cases. However, other cases, such as where the central bank sometimes wrongly believes that an asset is overpriced, are also of interest (see Kai and Conlon, 2008). ${ }^{10}$

In addition, this paper focuses only on the microeconomic aspects of bubble policy. Future work should study endogenous bubbles in a macroeconomic context, to shed light on their role in countercyclical policy (Bernanke and Gertler, 1999, 2001, Bordo and Jeanne, 2002, Cecchetti and coauthors, 2000, 2003).

In the present model, the potential distortion is a misallocation of produced capital - e.g., a stock market boom may encourage excessive investment in anticipation of an IPO. This has, in fact, been a major concern of policy makers. For example, at the July 1-2, 1997 FOMC meeting, President Minehan of the Boston Fed argued, "[w]e all know what happens when asset bubbles occur in financial and real estate markets.

... Banks begin lending for any project, viable or not. Everyone who can pick up a

10 Of course, opinions differ sharply about whether central bank concerns about overpricing are ever justified. However, since bubble bursting policy is one of the most widely discussed issues in central banking, it is clearly important, at least hypothetically, to consider the theoretical issues surrounding this important debate. Of course, it should be noted that, even if central bank announcements do move prices, this may be because they signal future policy intentions, not actual information about assets. 
hammer becomes a construction worker" (p. 122). Similarly, Swedish central bank governor Stefan Ingves (2007) argues that anti-bubble policy "can dampen the effects of the unmotivated price change on the real economy and thereby prevent an inefficient allocation of resources" (p. 437). Of course, models with other types of distortion would also be an important topic of future research. ${ }^{11}$

Finally, this paper examines policy in the simplest possible models. For example, we limit our analysis to a three-period world, with a bubble only in period one. This makes the timing of policy very rigid. In particular, "bubble bursting" really means bubble prevention - i.e., prevention of the first-period bubble. Thus, we cannot study the effects of delayed policy actions. While our results should generalize, it is important to determine what other issues also arise in more complicated models.

The next section introduces the basic asset market model. Section 2 studies general deflation of overpriced assets while Section 3 considers bubble bursting proper. Section 4 briefly discusses agent irrationality and Section 5 concludes.

\section{PRELIMINARIES}

This section presents the basic asset market model. The framework is similar to Milgrom and Stokey (1982), Allen et al. (1993) and Conlon (2004).

There are two risk neutral individuals in the market, Ellen and Frank, and a finite set of states of the world, $\Omega$. A typical state of the world is $\omega \in \Omega$. We also use symbols

11 There has been some disagreement as to whether managers increase investment in response to overpriced assets. Blanchard et al. (1993, p. 115) find that overpricing plays "at most a limited role in affecting investment decisions," while Chirinko and Schaller (2001), Panageas (2003), and Gilchrist, et al. (2005) find stronger evidence that asset overpricing encourages overinvestment. In Dupor (2005), like here, anti-bubble policy prevents bubbles from leading to overinvestment, though, since his bubble is exogenous, his model does not capture the lemons effect. See also Bolton, et al. (2005) for a model where managers encourage a bubble and then overinvest. 
such as $b, e^{B}, f_{2}^{G}$, etc., to denote states of the world. To make the modeling strategy as conservative as possible, assume that Ellen and Frank have a common prior probability distribution, $\pi(\omega)$, over $\Omega$.

In addition, Ellen and Frank have state-dependent marginal utilities, $M U_{E}(\omega)$ and $M U_{F}(\omega)$. Here $M U_{E}(\omega)$ and $M U_{F}(\omega)$ may differ because Ellen and Frank have different underlying future wealths in different states of the world, due, say, to risky future labor income. However, the marginal utility of wealth in each state is at least locally constant, independent of the outcome of trade in this market. That is, $M U_{E}(\omega)$ and $M U_{F}(\omega)$ depend only on $\omega$, and not on the wealth obtained from this market. Thus, the utility function must be at least piecewise linear (see Allen et al., 1993). Let

$$
M_{E}(\omega)=\frac{M U_{E}(\omega) \pi(\omega)}{\sum_{\omega^{\prime} i n \Omega} M U_{E}\left(\omega^{\prime}\right) \pi\left(\omega^{\prime}\right)} \text { and } M_{F}(\omega)=\frac{M U_{F}(\omega) \pi(\omega)}{\sum_{\omega^{\prime} i n \Omega} M U_{F}\left(\omega^{\prime}\right) \pi\left(\omega^{\prime}\right)}
$$

be shadow state prices indicating the ex ante value that Ellen and Frank attach to a unit of consumption in state $\omega$. We condense sums like $M_{E}\left(\omega_{1}\right)+\ldots+M_{E}\left(\omega_{k}\right)$ as $M_{E}\left(\omega_{1}, \ldots, \omega_{k}\right)$ for short, and similarly for $M_{F}\left(\omega_{1}, \ldots, \omega_{k}\right)$.

Note that $M_{E}(\omega)$ is the Arrow-Debreu price of a dollar in state $\omega$, that would prevail in an economy with representative agent Ellen, and similarly for $M_{F}(\omega)$ (Arrow, 1964). Thus, $M_{E}(\cdot)$ and $M_{F}(\cdot)$ resemble Equivalent Martingale probability measures (Harrison and Kreps, 1979). This means that Ellen's (Frank's) willingness to pay for an asset is simply given by the asset's conditional expected next-period value, based on the artificial probabilities $M_{E}(\cdot)$ (respectively, $M_{F}(\cdot)$ ). See (3) and (4) below.

The market lasts for three periods, denoted $t=1,2,3$, but there is no discounting. There is a riskless asset (money), and a risky asset. A unit of the risky asset ultimately, in period 3, pays a single dividend of $d(\omega)$ in state $\omega$.

This paper allows the risky asset to be produced. For example, office buildings can be constructed and entrepreneurs can expand their firms in anticipation of an IPO. 
Thus, in certain states, $\omega \in \Omega_{E}$, Ellen can produce an amount of the asset, $a$, at cost $c(a)$, with $c(0)=0$. In other states she cannot produce. Similarly, Frank can only produce in states $\omega \in \Omega_{F}$, also at $\operatorname{cost} c(a)$. All production occurs before period $t=1$, but after the central bank makes any announcements. For the fixed endowment case, $c(a)$ is zero up to the endowment point, and infinity thereafter. The initial amounts of the risky asset, after production, are denoted by $a_{0}^{E}(\omega)$ and $a_{0}^{F}(\omega)$, for Ellen and Frank, respectively. Of course, $a_{0}^{E}(\omega)=0$ for $\omega \notin \Omega_{E}$, and similarly for Frank. Ellen and Frank also begin with state-dependent endowments of money, $m_{0}^{E}(\omega)$ and $m_{0}^{F}(\omega)$.

Denote Ellen's and Frank's net sales of the risky asset in period $t$ by $x_{t}^{E}(\omega)$ and $x_{t}^{F}(\omega)$. Thus, if $a_{t}^{E}(\omega)$ and $a_{t}^{F}(\omega)$ are their holdings of the risky asset at the end of period $t$, then $a_{t}^{E}(\omega)=a_{t-1}^{E}(\omega)-x_{t}^{E}(\omega)$ for Ellen, and similarly for Frank. In the same way, if $m_{t}^{E}(\omega)$ and $m_{t}^{F}(\omega)$ are Ellen's and Frank's money holdings at the end of period $t$, and $p_{t}(\omega)$ is the price of the risky asset in period $t$ and state $\omega$, then $m_{t}^{E}(\omega)$ $=m_{t-1}^{E}(\omega)+p_{t}(\omega) x_{t}^{E}(\omega)$ for Ellen, and similarly for Frank. Assume that there are no short sales of the risky asset, so $a_{t}^{E}(\omega) \geq 0$ and $a_{t}^{F}(\omega) \geq 0$ for all $\omega$ and $t .^{12}$

Assume that the price of the consumption good, in terms of money, is fixed at one. Since marginal utilities are locally constant, the overall expected payoff to Ellen, say,

12 Many models of asset markets assume short-sale constraints (Harrison and Kreps, 1978, Tirole, 1982, Allen et al., 1993). As Shiller (2000), p. 244, explains, "[w]hen a ridiculous fad develops for some stocks ... most investors ... do no more than avoid those stocks: They do not take the kind of massive short positions ... that would fully offset the overly exuberant prices that the fad investors would create." See also Ofek and Richardson (2003) and Jones and Lamont (2002) who relate short selling costs to asset overpricing. More generally, if short sales are especially difficult in certain markets, e.g., real estate, then bubbles may be more likely in those markets.

Put options may play a role similar to short sales. Asquith et al. (2004), p. 30, however, argue that "[h]edge fund managers and other practitioners involved in short selling maintain that they can not effectively use the options market. In interviews, they repeatedly claimed that the options market provides less liquidity and is more expensive than the short sales market when trying to establish a large position." 
based on the value of her portfolio in period 3 , is then

$$
E^{\pi}\left[M U_{E}(\omega)\left[m_{3}^{E}(\omega)+a_{3}^{E}(\omega) d(\omega)-c\left(a_{0}^{E}(\omega)\right)\right]\right]
$$

where $E^{\pi}$ is the expectation with respect to the prior $\pi$, and similarly for Frank.

The models below have rich information structures. As is common in such models, we represent agents' information using information partitions. ${ }^{13}$ A partition of the set $\Omega$ is a set of subsets, $S_{i}$, of $\Omega$, such that the subsets are all disjoint $\left(S_{i} \cap S_{j}=\emptyset\right.$ for $\left.i \neq j\right)$, but they cover $\Omega\left(\cup_{i} S_{i}=\Omega\right)$. The partition $\left\{S_{i}\right\}$ is an agent's information partition if the agent knows which subset, $S_{i}$, the true state is in, but she cannot distinguish between different elements of $S_{i}$. For example, if $\omega_{1}$ is the actual state of the world, and $\omega_{1} \in S_{3}$, say, then the agent knows that the state is in $S_{3}$, but she does not know whether the true state is $\omega_{1}$ or some other state, $\omega_{2}$, say, in $S_{3}$. The subsets, $S_{i}$, of an information partition are called "cells" or "information sets." These information partitions can represent rich information structures. ${ }^{14}$

13 See Milgrom and Stokey (1982). For expository treatments, see Huang and Litzenberger (1988), Binmore (1992), or Samuelson (2004).

14 As an example, suppose $\Omega=\left\{\omega_{1}, \omega_{2}, \omega_{3}, \omega_{4}\right\}$, and assume that Ellen has an information partition $\left\{E_{1}, E_{2}\right\}$ with $E_{1}=\left\{\omega_{1}, \omega_{3}\right\}$ and $E_{2}=\left\{\omega_{2}, \omega_{4}\right\}$. This indicates that, if the true state of the world is $\omega_{2}$, for example, then Ellen knows that either $\omega_{2}$ or $\omega_{4}$ is the true state, but she does not know which one.

Next let Frank's partition be $\left\{F_{1}, F_{2}\right\}$, where $F_{1}=\left\{\omega_{1}, \omega_{2}, \omega_{3}\right\}$ and $F_{2}=\left\{\omega_{4}\right\}$. Assume these partitions are "common knowledge," so Ellen knows Frank's partition, Frank knows Ellen's partition, Ellen knows that Frank knows Ellen's partition, and so on. However, agents are not told the actual piece of information the other received. This sort of common knowledge assumption is standard in the literature.

Suppose the true state is $\omega_{1}$. Then Ellen knows the state is one of $\omega_{1}$ or $\omega_{3}$. Thus, Ellen knows the state is in Frank's cell $F_{1}=\left\{\omega_{1}, \omega_{2}, \omega_{3}\right\}$, so she knows that Frank thinks the state might be $\omega_{2}$. Also, since Frank thinks the state might be $\omega_{2}$, he incorrectly thinks that Ellen might think the state might be $\omega_{4}$. Thus, Ellen knows the state is not $\omega_{4}$, but she also knows that Frank thinks she might think the state might be $\omega_{4}$. This type of "higher order" thinking is essential for greater fool bubble models 
Ellen's and Frank's information partitions evolve over time as they get new information, with their underlying information partitions in period $t$ given by $\mathbf{E}_{t}=\left\{E_{i t}\right\}$ and $\mathbf{F}_{t}=\left\{F_{i t}\right\}$. These partitions incorporate any previous information that Ellen or Frank have (e.g., from $\Omega_{E}, \Omega_{F}, m_{0}^{E}(\omega)$ and $m_{0}^{E}(\omega)$ ). They also become (at least weakly) more informative over time, so Ellen and Frank do not forget. Ellen and Frank can also learn from current and previous market prices. The partitions also incorporating this additional price information will be denoted by $\mathbf{E}_{t}^{P}=\left\{E_{i t}^{P}\right\}$ and $\mathbf{F}_{t}^{P}=\left\{F_{i t}^{P}\right\}$. Finally, assume that all information is revealed by period 3 .

A competitive equilibrium in this market consists of a state-dependent pricing function, $p_{t}(\omega)$, and a pair of state-dependent net sales functions, $x_{t}^{E}(\omega)$ and $x_{t}^{F}(\omega)$, for Ellen and Frank, such that:

(i) $p_{t}(\omega)$ depends only on information possessed by Ellen or Frank at time $t$, i.e., on information in the coarsest common refinement of the partitions $\mathbf{E}_{t}$ and $\mathbf{F}_{t}$,

(ii) each agent's net trades depend only on information he/she actually possesses at the time of trade, so Ellen's (Frank's) net trades in period $t$ depend on information in her (his) price-refined partition, $\mathbf{E}_{t}^{P}\left(\mathbf{F}_{t}^{P}\right)$,

(iii) the market clears, so $x_{t}^{E}(\omega)+x_{t}^{F}(\omega)=0$, and

(iv) each agent's net trades are optimal, given his/her information, the set of statedependent prices, the short-sales constraints, and his/her (correct) beliefs about the other's strategy rule.

Follow Allen et al. (1993) by saying that a strong bubble exists at a state, $\omega$, if all agents know that the risky asset is overpriced for sure. Thus, if a strong bubble exists at state $\omega$ and time $t$, then Ellen, say, knows that the asset is overpriced, so $\omega \in E_{i t}^{P}$ implies that, for all $\omega^{\prime} \in E_{i t}^{P}, p_{t}\left(\omega^{\prime}\right)>d\left(\omega^{\prime}\right)$. That is, if the state is $\omega$, Ellen might (see Allen et al., 1993, Morris et al., 1995, Brunnermeier, 2001, or Conlon, 2004). 
not know that the state is $\omega$, but she does know which cell, $E_{i t}^{P}, \omega$ is in, and, for every state, $\omega^{\prime}$ in $E_{i t}^{P}$, the asset is overpriced. A similar condition must hold for Frank.

We next derive formulas for $p_{t}(\omega), t=1,2,3$. For $t=3$, price equals the dividend, since both agents have complete information. This means that $p_{3}(\omega)=d(\omega)$.

To obtain $p_{2}(\omega)$, suppose a buyer, Ellen say, is considering buying one more unit of the risky asset at information set $E_{i 2}^{P}$ in period 2. Since $E_{i 2}^{P}$ incorporates price information, $p_{2}(\omega)$ will be constant on $E_{i 2}^{P}$. Denote this constant by $p_{2}$. Then if Ellen buys this unit, her expected utility will change by

$$
\Delta E U_{E}=\sum_{\omega^{\prime} \in E_{i 2}^{P}} M U_{E}\left(\omega^{\prime}\right) \pi\left(\omega^{\prime}\right) d\left(\omega^{\prime}\right)-\sum_{\omega^{\prime} \in E_{i 2}^{P}} M U_{E}\left(\omega^{\prime}\right) \pi\left(\omega^{\prime}\right) p_{2} .
$$

This is the expected marginal utility, from dividends, of holding one more unit of the asset in period 3 , minus the expected marginal utility cost of holding $p_{2}$ units less money, both at information set $E_{i 2}^{P}$.

Ellen buys if $\Delta E U_{E} \geq 0$, but she has infinite demand if $\Delta E U_{E}>0$. She therefore buys a positive but finite amount only if $\Delta E U_{E}=0$. This yields

$$
p_{2}(\omega)=\frac{\sum_{\omega^{\prime} \in E_{i 2}^{P}} M U_{E}\left(\omega^{\prime}\right) \pi\left(\omega^{\prime}\right) d\left(\omega^{\prime}\right)}{\sum_{\omega^{\prime} \in E_{i 2}^{P}} M U_{E}\left(\omega^{\prime}\right) \pi\left(\omega^{\prime}\right)}=\frac{\sum_{\omega^{\prime} \in E_{i 2}^{P}} M_{E}\left(\omega^{\prime}\right) d\left(\omega^{\prime}\right)}{\sum_{\omega^{\prime} \in E_{i 2}^{P}} M_{E}\left(\omega^{\prime}\right)}
$$

for all $\omega \in E_{i 2}^{P}$. This is the equilibrium period 2 price if Ellen is buying, or more generally, if Ellen is not short-sale constrained. Similarly, if Ellen is not short-sale constrained in period 1 and information set $E_{i 1}^{P}$, then

$$
p_{1}(\omega)=\frac{\sum_{\omega^{\prime} \in E_{i 1}^{P}} M_{E}\left(\omega^{\prime}\right) p_{2}\left(\omega^{\prime}\right)}{\sum_{\omega^{\prime} \in E_{i 1}^{P}} M_{E}\left(\omega^{\prime}\right)} \text { for all } \omega \in E_{i 1}^{P} .
$$

Similar formulas hold if Frank is not short-sale constrained. Note that (3) and (4) are essentially conditional expectations, based on the artificial probabilities $M_{E}(\omega)$.

Finally, note that the elasticity of demand is infinite at the equilibrium price, so expected consumer surplus must be zero. Expected welfare therefore simply equals the appropriately weighted expected producer surplus. 


\section{GENERAL DEFLATION OF OVERPRICED ASSETS}

This section presents a simple example of a bubble. It also examines a policy of "general deflation of overpriced assets," where, if any investors know an asset is overpriced, then, with probability $\lambda$, the central bank also knows this, and announces its information. This is not yet "bubble bursting," since some investors may not know the asset is overpriced. Thus, general deflation of overpriced assets can protect these uninformed investors from the informed investors, and so, tends to increase welfare. We first present the basic model and equilibrium, and then analyze policy.

\section{A. Basic Setup and Equilibrium}

We first give some intuition for the bubble model. There are two traders, Ellen and Frank. In some states of the world Ellen is a "bad seller" who wants to sell Frank an asset she knows is worthless. In other states Ellen is a "good seller," who believes that the asset may be valuable, but is willing to sell it to Frank because he is willing to pay more for it than she is. Frank is willing to buy the asset from Ellen, even though she might be a bad seller, because there are potential gains from trade if she is good, and Frank cannot distinguish between states where Ellen is a good versus a bad seller.

Symmetrically, there are certain states in which Frank is a good or bad seller, and Ellen is willing to buy in some of these states, since she cannot distinguish between states where Frank is good versus bad. Finally, in certain of the bad states, both know the asset is worthless, but each is willing to hold it in the (mistaken) belief that he/she will be able to sell it later. A strong bubble therefore exists in those states.

In certain of the bad states, the central bank also knows the asset is worthless. This subsection assumes that the central bank does not reveal its information, while the next subsection assumes the central bank announces these states if they occur.

Assume that there are twelve possible states of nature,

$$
\Omega=\left\{b, b_{C B}, e^{B}, e_{C B}^{B}, f^{B}, f_{C B}^{B}, e_{1}^{G}, e_{2}^{G}, e_{3}^{G}, f_{1}^{G}, f_{2}^{G}, f_{3}^{G}\right\} .
$$


The letter $b$ indicates a potential bubble state, while the letters $e$ versus $f$ indicate whether Ellen alone or Frank alone can produce the asset in that state. Superscripts $B$ versus $G$ indicate whether the seller is bad (so he/she knows the asset is worthless) or good (so he/she thinks it might be valuable). Finally, the subscript $C B$ indicates that the central bank knows the asset is worthless in that state, and the subscripts on $e_{i}^{G}$ and $f_{i}^{G}$ affect the timing of information, as explained below. More specifically, assume Ellen (Frank) can produce the asset in states $\omega \in \Omega_{E}\left(\omega \in \Omega_{F}\right)$, where

$$
\begin{aligned}
& \Omega_{E}=\left\{b, b_{C B}, e^{B}, e_{C B}^{B}, e_{1}^{G}, e_{2}^{G}, e_{3}^{G}\right\}, \\
& \Omega_{F}=\left\{b, b_{C B}, f^{B}, f_{C B}^{B}, f_{1}^{G}, f_{2}^{G}, f_{3}^{G}\right\},
\end{aligned}
$$

and the central bank knows whether or not the state of the world is in

$$
\Omega_{C B}=\left\{b_{C B}, e_{C B}^{B}, f_{C B}^{B}\right\}
$$

Assume the asset only pays a nonzero dividend in states $e_{3}^{G}$ and $f_{3}^{G}$, and this dividend is $d\left(e_{3}^{G}\right)=d\left(f_{3}^{G}\right)=d$. Note that the dividend is zero in $\Omega_{C B}$. Thus, if the central bank learns that $\omega \in \Omega_{C B}$ and announces this, this information becomes common knowledge, and the price falls to zero. However, this subsection assumes that the central bank does not make any announcements.

For simplicity, assume symmetry in probabilities and marginal utilities. Thus, for probabilities assume $\pi\left(e^{B}\right)=\pi\left(f^{B}\right), \pi\left(e_{C B}^{B}\right)=\pi\left(f_{C B}^{B}\right)$, and $\pi\left(e_{i}^{G}\right)=\pi\left(f_{i}^{G}\right)$ for $i=$ 1, 2, 3. Similarly, for marginal utilities assume symmetries such as $M U_{E}(b)=M U_{F}(b)$, $M U_{E}\left(e^{B}\right)=M U_{F}\left(f^{B}\right), M U_{E}\left(f_{i}^{G}\right)=M U_{F}\left(e_{i}^{G}\right)$, and so on. These symmetries imply the following symmetries for the shadow state prices $M_{E}$ and $M_{F}$ :

$$
\begin{gathered}
M_{E}(b)=M_{F}(b), M_{E}\left(b_{C B}\right)=M_{F}\left(b_{C B}\right), M_{E}\left(e^{B}\right)=M_{F}\left(f^{B}\right), \\
M_{E}\left(f^{B}\right)=M_{F}\left(e^{B}\right), M_{E}\left(e_{C B}^{B}\right)=M_{F}\left(f_{C B}^{B}\right), M_{E}\left(f_{C B}^{B}\right)=M_{F}\left(e_{C B}^{B}\right), \\
M_{E}\left(e_{i}^{G}\right)=M_{F}\left(f_{i}^{G}\right), \text { and } M_{E}\left(f_{i}^{G}\right)=M_{F}\left(e_{i}^{G}\right), i=1,2,3 .
\end{gathered}
$$


We next indicate what Ellen and Frank know, using their information partitions, $\mathbf{E}_{t}=\left\{E_{i t}\right\}$ and $\mathbf{F}_{t}=\left\{F_{i t}\right\}$. Let Ellen's underlying period 1 information partition be

$$
\begin{gathered}
E_{\text {Seller }}^{B}=\left\{b, b_{C B}, e^{B}, e_{C B}^{B}\right\}, \quad E_{\text {Seller }}^{G}=\left\{e_{1}^{G}, e_{2}^{G}, e_{3}^{G}\right\}, \\
E_{\text {Buyer }}=\left\{f^{B}, f_{C B}^{B}, f_{1}^{G}, f_{2}^{G}, f_{3}^{G}\right\},
\end{gathered}
$$

while Frank's underlying information partition is

$$
\begin{gathered}
F_{\text {Seller }}^{B}=\left\{b, b_{C B}, f^{B}, f_{C B}^{B}\right\}, F_{\text {Seller }}^{G}=\left\{f_{1}^{G}, f_{2}^{G}, f_{3}^{G}\right\} \\
F_{\text {Buyer }}=\left\{e^{B}, e_{C B}^{B}, e_{1}^{G}, e_{2}^{G}, e_{3}^{G}\right\} .
\end{gathered}
$$

These partitions are illustrated in Figure 1.

Note that we left the time subscript $t=1$ off of the information sets for simplicity. Note also that Ellen can produce the risky asset in the cells $E_{S e l l e r}^{B}$ and $E_{\text {Seller }}^{G}$, and Frank can produce it in the cells $F_{\text {Seller }}^{B}$ and $F_{\text {Seller }}^{G}$. Thus, both agents know whether or not they can produce the risky asset.

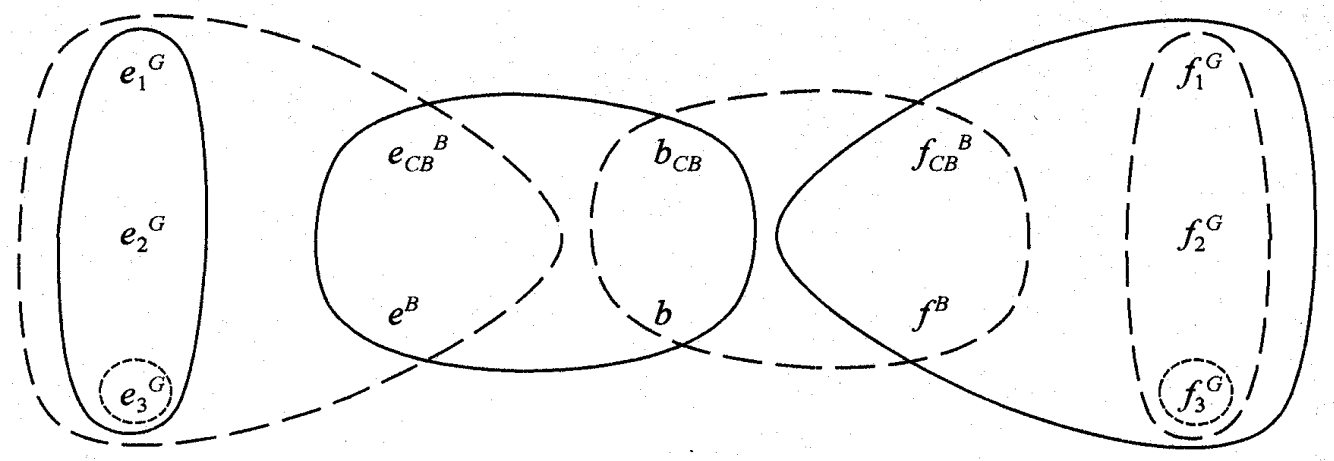

Figure 1: Information Partitions: Ellen's - Solid Lines, Frank's - Dashed Lines. Dividend Paying States - Dotted Lines.

The cell $E_{\text {Seller }}^{B}$ will contain states where Ellen is a bad seller, who hopes to sell an asset she knows is worthless, and $E_{\text {Seller }}^{G}$ will contain states where Ellen is a good seller, who hopes to sell an asset she thinks may be valuable, i.e., may pay a positive 
dividend. Also, note that Frank - in cell $F_{\text {Buyer }}$ - cannot distinguish between the good states in $E_{\text {Seller }}^{G}$, and two bad states, $e^{B}$ and $e_{C B}^{B}$, from $E_{\text {Seller }}^{B}$. This is why Frank may be willing to buy from Ellen in states $e^{B}$ and $e_{C B}^{B}$, where she is bad. Similarly, Ellen may be willing to buy from Frank in states $f^{B}$ and $f_{C B}^{B}$, where he is bad.

In period 2 , both players learn the true state, $\omega$, if it is $b, b_{C B}, e_{1}^{G}$, or $f_{1}^{G}$. Ellen's and Frank's underlying information partitions in period 2 are therefore:

$$
\begin{gathered}
E_{12}^{0}=\{b\}, E_{22}^{0}=\left\{b_{C B}\right\}, E_{32}^{0}=\left\{e_{1}^{G}\right\}, E_{42}^{0}=\left\{f_{1}^{G}\right\} \\
E_{\text {Seller } 2}^{B}=\left\{e^{B}, e_{C B}^{B}\right\}, E_{\text {Seller } 2}^{G}=\left\{e_{2}^{G}, e_{3}^{G}\right\}, E_{\text {Buyer } 2}=\left\{f^{B}, f_{C B}^{B}, f_{2}^{G}, f_{3}^{G}\right\}, \\
F_{12}^{0}=\{b\}, F_{22}^{0}=\left\{b_{C B}\right\}, F_{32}^{0}=\left\{f_{1}^{G}\right\}, F_{42}^{0}=\left\{e_{1}^{G}\right\} \\
F_{\text {Seller } 2}^{B}=\left\{f^{B}, f_{C B}^{B}\right\}, F_{\text {Seller } 2}^{G}=\left\{f_{2}^{G}, f_{3}^{G}\right\}, F_{\text {Buyer } 2}=\left\{e^{B}, e_{C B}^{B}, e_{2}^{G}, e_{3}^{G}\right\} .
\end{gathered}
$$

Note that we include the time subscript $t=2$. Also, in the cells $E_{12}^{0}, E_{22}^{0}, E_{32}^{0}, E_{42}^{0}$, $F_{12}^{0}, F_{22}^{0}, F_{32}^{0}$, and $F_{42}^{0}$, it is common knowledge that the asset is worthless, so the price will be zero. Thus, the only interesting cells are $E_{\text {Seller } 2}^{B}, E_{\text {Seller } 2}^{G}$, and $E_{\text {Buyer2 } 2}$ for Ellen, and $F_{\text {Seller } 2}^{B}, F_{\text {Seller } 2}^{G}$, and $F_{\text {Buyer } 2}$ for Frank (see Figure 2). In period 3 Ellen and Frank learn the true state no matter what it is.
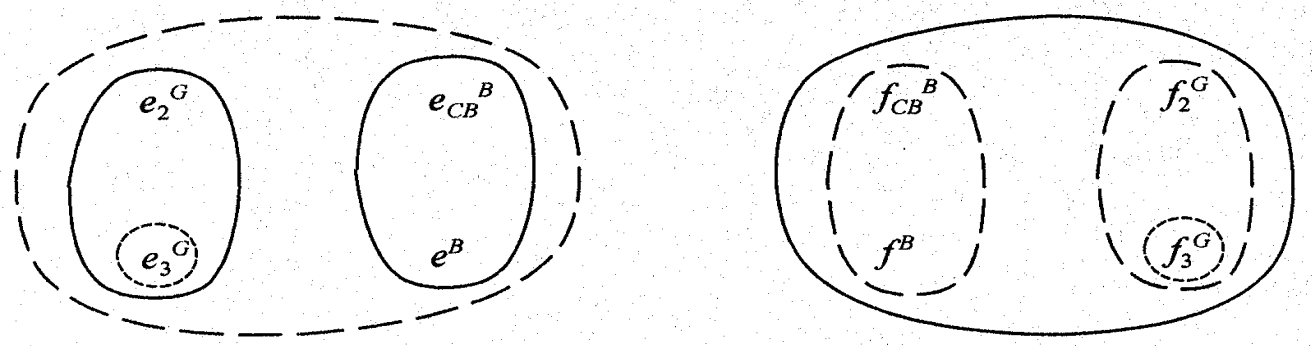

Figure 2: The Interesting Period 2 Information Sets: Ellen's - Solid Lines, Frank's Dashed Lines. Dividend Paying States - Dotted Lines.

Recall that the asset only pays a nonzero dividend in states $e_{3}^{G}$ and $f_{3}^{G}$. Thus, when Ellen observes the event $E_{\text {Seller }}^{B}=\left\{b, b_{C B}, e^{B}, e_{C B}^{B}\right\}$, she knows that the asset is 
actually worthless, and when Frank observes the event $F_{S e l l e r}^{B}=\left\{b, b_{C B}, f^{B}, f_{C B}^{B}\right\}$, he knows that the asset is worthless. This implies that, in states $b$ and $b_{C B}$, both Ellen and Frank know that the asset is worthless, though neither knows that the other knows. Thus, if the price of the asset is nevertheless positive in these states, this will represent a strong bubble in the sense of Allen et al. (1993).

We now construct an equilibrium with a strong bubble in states $b$ and $b_{C B}$. Table 1 presents the general pattern of prices in this equilibrium. Proposition 1 determines equilibrium prices $p_{1}$ and $p_{2}$, and indicates the conditions needed to sustain this equilibrium. Throughout we focus primarily on the states $b, b_{C B}, e^{B}, e_{C B}^{B}$ and the $e_{i}^{G}$, where Ellen hopes to sell to Frank. By symmetry (see (8)), the same results will automatically apply to states where Frank hopes to sell to Ellen.

\section{TABLE 1: EQUILIBRIUM PRICES}

\begin{tabular}{|c|c|c|c|c|c|c|c|c|c|c|c|c|}
\hline$\omega$ & $b$ & $b_{C B}$ & $e^{B}$ & $e_{C B}^{B}$ & $f^{B}$ & $f_{C B}^{B}$ & $e_{1}^{G}$ & $e_{2}^{G}$ & $e_{3}^{G}$ & $f_{1}^{G}$ & $f_{2}^{G}$ & $f_{3}^{G}$ \\
\hline$p_{1}(\omega)$ & $p_{1}$ & $p_{1}$ & $p_{1}$ & $p_{1}$ & $p_{1}$ & $p_{1}$ & $p_{1}$ & $p_{1}$ & $p_{1}$ & $p_{1}$ & $p_{1}$ & $p_{1}$ \\
$p_{2}(\omega)$ & 0 & 0 & $p_{2}$ & $p_{2}$ & $p_{2}$ & $p_{2}$ & 0 & $p_{2}$ & $p_{2}$ & 0 & $p_{2}$ & $p_{2}$ \\
$p_{3}(\omega)$ & 0 & 0 & 0 & 0 & 0 & 0 & 0 & 0 & $d$ & 0 & 0 & $d$ \\
\hline
\end{tabular}

PROPOSITION 1: Suppose that $M_{E}$ and $M_{F}$ satisfy the three conditions

$$
\begin{gathered}
\frac{M_{E}\left(e_{2}^{G}, e_{3}^{G}\right)}{M_{E}\left(e_{1}^{G}, e_{2}^{G}, e_{3}^{G}\right)}=\frac{M_{E}\left(e^{B}, e_{C B}^{B}\right)}{M_{E}\left(b, b_{C B}, e^{B}, e_{C B}^{B}\right)}, \\
\frac{M_{E}\left(e_{2}^{G}, e_{3}^{G}\right)}{M_{E}\left(e_{1}^{G}, e_{2}^{G}, e_{3}^{G}\right)} \geq \frac{M_{F}\left(e^{B}, e_{C B}^{B}, e_{2}^{G}, e_{3}^{G}\right)}{M_{F}\left(e^{B}, e_{C B}^{B}, e_{1}^{G}, e_{2}^{G}, e_{3}^{G}\right)},
\end{gathered}
$$

and

$$
\frac{M_{F}\left(e_{3}^{G}\right)}{M_{F}\left(e^{B}, e_{C B}^{B}, e_{2}^{G}, e_{3}^{G}\right)} \geq \frac{M_{E}\left(e_{3}^{G}\right)}{M_{E}\left(e_{2}^{G}, e_{3}^{G}\right)}
$$

Then the prices in Table 1 form an equilibrium, where $p_{1}$ and $p_{2}$ are given as

$$
p_{1}=\frac{M_{E}\left(e_{2}^{G}, e_{3}^{G}\right)}{M_{E}\left(e_{1}^{G}, e_{2}^{G}, e_{3}^{G}\right)} p_{2}
$$


and

$$
p_{2}=\frac{M_{F}\left(e_{3}^{G}\right)}{M_{F}\left(e^{B}, e_{C B}^{B}, e_{2}^{G}, e_{3}^{G}\right)} d
$$

Ellen and Frank produce $a^{*}$ in $\Omega_{E}$ and $\Omega_{F}$, respectively, where $a^{*}=a^{*}\left(p_{1}\right)$ satisfies $c^{\prime}\left(a^{*}\right)=p_{1}$. In period 2, Ellen sells $a^{*}$ to Frank in states $e^{B}, e_{C B}^{B}, e_{2}^{G}$, and $e_{3}^{G}$ and Frank sells $a^{*}$ to Ellen in states $f^{B}, f_{C B}^{B}, f_{2}^{G}$, and $f_{3}^{G}$.

PROOF: See Appendix A.

Note that conditions symmetrical to (13), (14) and (15) follow automatically from the symmetries in (8). These conditions have the following interpretations:

Condition (13) says that, in period 1, Ellen bids up the price, $p_{1}$, to the same levels at information sets $E_{\text {Seller }}^{B}=\left\{b, b_{C B}, e^{B}, e_{C B}^{B}\right\}$, and $E_{\text {Seller }}^{G}=\left\{e_{1}^{G}, e_{2}^{G}, e_{3}^{G}\right\}$. This condition is necessary so that bad Ellen pools with good Ellen, i.e., Ellen's behavior in period 1 does not reveal to buyer Frank whether she is good or bad. This requires a coincidence between different shadow state prices for Ellen, so this equilibrium is not robust to variations in model parameters (but see Subsection 3.A below).

Condition (14) says that future seller Ellen bids first period price $p_{1}$ up more at information set $E_{\text {Seller }}^{G}=\left\{e_{1}^{G}, e_{2}^{G}, e_{3}^{G}\right\}\left(\right.$ and so, also at $\left.E_{\text {Seller }}^{B}=\left\{b, b_{C B}, e^{B}, e_{C B}^{B}\right\}\right)$ than does future buyer Frank at his overlapping information set $F_{\text {Buyer }}=\left\{e^{B}, e_{C B}^{B}\right.$, $\left.e_{1}^{G}, e_{2}^{G}, e_{3}^{G}\right\}$. This requires Frank to initially be more concerned about falling prices than good seller Ellen. Frank is then short-sale constrained in period 1 at $F_{\text {Buyer }}$, so his preferences do not affect the market price. This is necessary so that bad seller Ellen, at $E_{\text {Seller }}^{B}=\left\{b, b_{C B}, e^{B}, e_{C B}^{B}\right\}$, cannot tell whether Frank is a buyer at $F_{B u y e r}$, or a bad seller at $F_{\text {Seller }}^{B}=\left\{b, b_{C B}, f^{B}, f_{C B}^{B}\right\}$.

Finally, condition (15) says that, in period 2, Frank, at information set $F_{\text {Buyer } 2}=$ $\left\{e^{B}, e_{C B}^{B}, e_{2}^{G}, e_{3}^{G}\right\}$, is willing to buy from good Ellen, at her information set $E_{\text {Seller } 2}^{G}=$ $\left\{e_{2}^{G}, e_{3}^{G}\right\}$, even though Frank thinks that Ellen might be a bad seller at information set $E_{\text {Seller } 2}^{B}=\left\{e^{B}, e_{C B}^{B}\right\}$. This requires there to be strictly positive gains from trade be- 
tween Frank and good Ellen, which requires Frank to put more weight on the dividendpaying state, $e_{3}^{G}$, than does good Ellen, so $M_{F}\left(e_{3}^{G}\right) / M_{F}\left(e_{2}^{G}\right)>M_{E}\left(e_{3}^{G}\right) / M_{E}\left(e_{2}^{G}\right)$. For example, Frank might expect very low future labor income in the dividend paying state $e_{3}^{G}$, and so, may consider the asset to be a good hedge against his future labor income, while Ellen may consider the asset to be a bad hedge against her future labor income.

Thus, when these conditions are met, future sellers bid $p_{1}$ up to (16) in the first period, and buyers bid $p_{2}$ up to (17) in the second period, and purchase at that price. ${ }^{15}$

As discussed at the end of the next subsection, there is also a second nonbubble equilibrium, with price always zero in states $b, b_{C B}, e^{B}, e_{C B}^{B}, f^{B}$, and $f_{C B}^{B}$.

\section{B. Policy Analysis}

We now examine the welfare effects of a policy of "general deflation of overpriced assets." Recall that $b_{C B}, e_{C B}^{B}$, and $f_{C B}^{B}$ are states where the central bank knows the asset is worthless, and assume now that the central bank announces whether $\omega$ is one of these states. The announcement is made before production, so central bank announcements - or their absence - can influence agents' production decisions. We analyze how this policy affects an agent's welfare in her different interim situations good seller, bad seller, or buyer. We also analyze her ex ante expected utility, i.e., from the viewpoint of an agent who has not yet received any information, so she does not know whether she is a good seller, a bad seller, or a buyer.

Let $0<\lambda<1$ be a parameter indicating the probability that the central bank knows the asset is overpriced, if at least one private agent knows this. Specifically, let

$$
\pi\left(b_{C B}\right)=\lambda \pi\left(b, b_{C B}\right), \quad \pi\left(e_{C B}^{B}\right)=\lambda \pi\left(e^{B}, e_{C B}^{B}\right), \quad \pi\left(f_{C B}^{B}\right)=\lambda \pi\left(f^{B}, f_{C B}^{B}\right) .
$$

${ }^{15}$ In terms of their roles in our discussion, (13) is not needed in richer models (see Subsection 3.A), while (14) assures that trade occurs in period 2, not period 1, and (15) generates a motive for trade in period 2. 
Also, to simplify the analysis, assume that the states $b$ and $b_{C B}$, etc, are identical in terms of marginal utilities, so $M U_{k}(b)=M U_{k}\left(b_{C B}\right), M U_{k}\left(e^{B}\right)=M U_{k}\left(e_{C B}^{B}\right)$, and $M U_{k}\left(f^{B}\right)=M U_{k}\left(f_{C B}^{B}\right)$, for $k=E, F$. This, combined with (18), implies that

$$
\begin{gathered}
M_{k}\left(b_{C B}\right)=\lambda M_{k}\left(b, b_{C B}\right), \quad M_{k}\left(e_{C B}^{B}\right)=\lambda M_{k}\left(e^{B}, e_{C B}^{B}\right), \text { and } \\
M_{k}\left(f_{C B}^{B}\right)=\lambda M_{k}\left(f^{B}, f_{C B}^{B}\right), \text { for } k=E, F .
\end{gathered}
$$

Suppose the central bank follows a policy of deflating overpriced assets, so it announces whether or not the state is one of $b_{C B}, e_{C B}^{B}$, or $f_{C B}^{B}$. Suppose also that the public understands this policy. Then, if the central bank announces $b_{C B}, e_{C B}^{B}$ or $f_{C B}^{B}$, it becomes common knowledge that the asset is worthless, and the price collapses.

Suppose, on the other hand, that the central bank turns out not to announce $b_{C B}$, $e_{C B}^{B}$ or $f_{C B}^{B}$. This is equivalent to announcing that the true state is not $b_{C B}, e_{C B}^{B}$ or $f_{C B}^{B}$. This reduces the probability of a bubble, where both know that the asset is worthless, by a factor of $1-\lambda$, from $\pi\left(b, b_{C B}\right)$ to $\pi(b)$. It also reduces, by the same factor, $1-\lambda$, the probability that Ellen alone knows the asset is worthless, from $\pi\left(e^{B}, e_{C B}^{B}\right)$ to $\pi\left(e^{B}\right)$, and similarly for Frank.

Thus, given that there is at least one bad seller who knows the asset is worthless, the central bank's information is not correlated with the number of bad sellers who know this. The next section considers the opposite extreme - bubble bursting - where the central bank's information is highly correlated with the number of bad sellers.

Since the central bank's information is uncorrelated with whether one versus two sellers are bad in this section, the central bank's announcement policy does not influence a bad seller's probability assessment of whether other agents are bad sellers. The central bank's policy therefore does not affect bad sellers' confidence levels, so bad sellers continue to pool with good sellers, and an equilibrium like the one in Proposition 1 continues to exist, as shown in Proposition 2. 
PROPOSITION 2: If shadow state prices satisfy (19) for some $\lambda$ between zero and one, then, under a policy of general deflation of overpriced assets, an equilibrium like that in Proposition 1 continues to exist, but with $p_{1}(\omega)=0$ at $\omega=b_{C B}, e_{C B}^{B}$ and $f_{C B}^{B}$, with $p_{2}(\omega)=0$ at $\omega=e_{C B}^{B}$ and $f_{C B}^{B}$, and with (17) replaced by

$$
p_{2}=\frac{M_{F}\left(e_{3}^{G}\right)}{M_{F}\left(e^{B}, e_{2}^{G}, e_{3}^{G}\right)} d .
$$

PROOF: First, equations (13) and (19) above imply that

$$
\frac{M_{E}\left(e_{2}^{G}, e_{3}^{G}\right)}{M_{E}\left(e_{1}^{G}, e_{2}^{G}, e_{3}^{G}\right)}=\frac{M_{E}\left(e^{B}\right)}{M_{E}\left(b, e^{B}\right)},
$$

since (19) implies that the right hand side of $\left(13^{\prime}\right)$ equals the right hand side of (13). Bad sellers therefore continue to pool with good sellers. Also, the analogue of (14) continues to hold if $e_{C B}^{B}$ is removed, since the right hand side becomes smaller. Similarly, the analogue of (15) continues to hold, since the left hand side becomes bigger. QED

Thus, a bubble equilibrium continues to exist in the presence of a policy of general deflation of overpriced assets. This policy rule has four major effects:

(a) In those states where an overpriced asset is deflated, producers do not waste resources producing the asset. This improves welfare.

(b) Bad sellers, who know the asset is worthless, cannot sell the asset if the central bank reveals it to be worthless. This hurts bad sellers, but helps buyers.

(c) In states where the central bank does not make a price deflating announcement, buyers become more confident that the asset is valuable, so they bid up $p_{2}$, so $p_{1}$ also rises. This helps sellers but hurts buyers.

(d) Effect (c) encourages production in states where the central bank does nothing.

Effects (b) and (c) are pure "transfer effects," while (a) and (d) influence production. For buyers, these effects must perfectly cancel, since their demand is infinitely elastic, so their expected consumer surplus remains constant at zero. For sellers, these 
effects may not cancel. The lower probability of selling worthless assets (effect (b)) hurts sellers, but the higher price (effect (c)) helps them. Thus, seller welfare could rise or fall. However, suppose transfer effects (b) and (c) exactly cancel. Then we will show that the improved allocation of production (less output in bad-seller states, from effect (a), more output in remaining states, from effect (d)) helps welfare.

Thus, consider Ellen's expected utility. Since her elasticity of demand is infinite in all states where she buys, her expected consumer surplus is zero in those states, whether the policy is in effect or not. Thus, her expected benefit from this market comes from profits in states where she produces. Since, by (16), she is indifferent between selling her output in period 1 and holding it for period 2, we can imagine, when calculating her expected utility, that she sells her output in period 1. Also, her profit from states where she produces is $p_{1} a^{*}\left(p_{1}\right)-c\left(a^{*}\left(p_{1}\right)\right)=\Pi\left(p_{1}\right)$.

We must compare her expected welfare with no deflation policy $(N D P)$ to that with deflation policy $(D P)$. Denote the value of $p_{1}$ in these two cases as $p_{1}^{N D P}$ and $p_{1}^{D P}$, respectively. Then using $(16),(17)$ and $\left(17^{\prime}\right)$,

$$
\frac{p_{1}^{D P}}{p_{1}^{N D P}}=\frac{M_{F}\left(e^{B}, e_{C B}^{B}, e_{2}^{G}, e_{3}^{G}\right)}{M_{F}\left(e^{B}, e_{2}^{G}, e_{3}^{G}\right)}
$$

so $p_{1}^{D P}>p_{1}^{N D P}$. This yields effect (c) above.

In the no-deflation-policy case, Ellen produces in states $b, b_{C B}, e^{B}, e_{C B}^{B}, e_{1}^{G}, e_{2}^{G}$, and $e_{3}^{G}$, so her expected welfare from this market is

$$
E U_{E}^{N D P}=\Pi\left(p_{1}^{N D P}\right) M_{E}\left(b, b_{C B}, e^{B}, e_{C B}^{B}, e_{1}^{G}, e_{2}^{G}, e_{3}^{G}\right)
$$

On the other hand, in the deflation-policy case, she produces only in states $b, e^{B}, e_{1}^{G}$, $e_{2}^{G}$, and $e_{3}^{G}$, so her expected welfare becomes

$$
E U_{E}^{D P}=\Pi\left(p_{1}^{D P}\right) M_{E}\left(b, e^{B}, e_{1}^{G}, e_{2}^{G}, e_{3}^{G}\right)
$$


To isolate transfer effects (b) and (c), consider first the case of a fixed endowment $e$, so $\Pi\left(p_{1}\right)=e p_{1}$. Proposition 3 determines the welfare effect of policy in this case.

PROPOSITION 3: In the fixed endowment case, general deflation of overpriced assets increases agents' expected welfare if and only if

$$
\frac{M_{E}\left(e_{C B}^{B}\right)}{M_{E}\left(e^{B}, e_{2}^{G}, e_{3}^{G}\right)}<\frac{M_{F}\left(e_{C B}^{B}\right)}{M_{F}\left(e^{B}, e_{2}^{G}, e_{3}^{G}\right)} .
$$

PROOF: See Appendix B.

Proposition 3 says that, for the fixed endowment case, the welfare of Ellen, say, will increase with a policy of general deflation of overpriced assets if Ellen attaches less weight to $\left\{e_{C B}^{B}\right\}$ relative to $\left\{e^{B}, e_{2}^{G}, e_{3}^{G}\right\}$ than does Frank. Of course, in the opposite case the central bank's information revelation hurts expected welfare. ${ }^{16}$

This may be understood as follows. First, in the fixed endowment case, effects (a) and (d) above go away, so just effects (b) and (c) remain. The policy then hurts Ellen but helps Frank in state $e_{C B}^{B}$, since it prevents Ellen from selling Frank a worthless asset in that state. On the other hand, the policy helps Ellen but hurts Frank by raising the price in states $e^{B}, e_{2}^{G}$ and $e_{3}^{G}$. For Frank, these effects must cancel, to keep his overall consumer surplus constant at zero. Thus, Ellen benefits on average if, as in (23), she puts less weight, relative to Frank, on state $e_{C B}^{B}$, where she suffers, than on states $e^{B}, e_{2}^{G}$ and $e_{3}^{G}$, where she benefits. That is, if (23) holds, policy transfers wealth from Ellen to Frank when Frank's marginal utility of consumption is relatively high, and from Frank to Ellen when Ellen's marginal utility of consumption is relatively high.

Finally, conditions (13) through (15) in Proposition 1 do not force inequality (23) to go either way, since they say nothing about how much weight Ellen puts on her good states, $e_{2}^{G}$ and $e_{3}^{G}$, relative to her bad state, $e_{C B}^{B}$.

16 This effect is related to that discussed in Hirshleifer (1972), p. 568, where information revelation disrupts insurance markets. 
Next take as a baseline the case where shadow state prices are chosen to eliminate transfer effects, so policy has no effect on expected welfare under fixed endowments. This is analogous to the standard practice of ignoring pure lump sum transfers in consumer/producer surplus analysis. In this case, $(21)$ equals $(22)$ for $\Pi\left(p_{1}\right)=e p_{1}$, so

$$
\text { Baseline Case : } \frac{p_{1}^{D P}}{p_{1}^{N D P}}=\frac{M_{E}\left(b, b_{C B}, e^{B}, e_{C B}^{B}, e_{1}^{G}, e_{2}^{G}, e_{3}^{G}\right)}{M_{E}\left(b, e^{B}, e_{1}^{G}, e_{2}^{G}, e_{3}^{G}\right)}
$$

Suppose (24) holds. Then, in the case where production is possible, a policy of general deflation of overpriced assets improves welfare, as shown in Proposition 4.

PROPOSITION 4: Suppose shadow state prices are such that a policy of general deflation of overpriced assets does not affect overall expected welfare in the fixed endowment case. Then if production is possible, so the supply curve $a^{*}\left(p_{1}\right)$ is upward sloping, a policy of general deflation of overpriced assets will increase welfare.

PROOF: First, by Hotelling's Lemma, $\Pi^{\prime}\left(p_{1}\right)=a^{*}\left(p_{1}\right)$ so, since $a^{*}\left(p_{1}\right)$ is increasing in $p_{1}$, the function $\Pi\left(p_{1}\right)$ is strictly convex. Also, $\Pi(0)=0$ (since $\left.c(0)=0\right)$. Thus, since $p_{1}^{D P}>p_{1}^{N D P}$, it follows that $\Pi\left(p_{1}^{D P}\right) / \Pi\left(p_{1}^{N D P}\right)>p_{1}^{D P} / p_{1}^{N D P}$. From this and (24) it follows that (22) is bigger than (21). QED

Intuitively, if (24) holds, so there is no transfer effect, then the only remaining welfare consequence of the price-deflation policy is better production decisions. This improvement has two aspects. First, since the central bank sometimes reveals when the asset is worthless, bad sellers waste less resources producing worthless assets (effect (a)). Second, in those states where the central bank makes no announcement, the lemons problem is reduced, so producers can produce more confidently (effect (d)).

Up to now, we have focused on the case where the policy rule shifts the economy from one bubble equilibrium to another. However, a nonbubble equilibrium also continues to exist in the presence of the policy, with price equal to zero in states $b, b_{C B}$, $e^{B}, e_{C B}^{B}, f^{B}$, and $f_{C B}^{B}$. While we cannot determine which equilibrium will prevail, the 
above framework allows us to analyze the effect of the policy in each case, regardless of whether the policy shifts the market into or out of a bubble equilibrium. This is because a nonbubble equilibrium is identical to the equilibrium in Proposition 2, but with $\lambda=1$ (so the central bank always deflates an asset someone knows is overpriced). For example, if the policy shifts the market from a bubble to a nonbubble equilibrium, the effect is as in Propositions 2 through 4, but with $\lambda=1$, so the effect is stronger. If the policy shifts the market from a nonbubble to a bubble equilibrium, the effect is reversed - like reducing $\lambda$ from $\lambda_{0}=1$ to some $\lambda_{1}<1$, and so on.

Of course, the fact that policy may shift the economy between bubble and nonbubble equilibria is important, since it may help to explain why policy sometimes has such unpredictable effects on asset markets.

In any case, unless a policy of general deflation of overpriced assets causes the economy to shift from a nonbubble to a bubble equilibrium, it improves production allocation decisions. This policy will therefore be beneficial overall unless the transfer effect is negative. By contrast, a bubble bursting policy is likely to worsen production allocation decisions, as shown next.

\section{BURSTING BUBBLES AND THE LEMONS PROBLEM}

\section{A. Comment on Robustness}

The above equilibria were not robust since they required the coincidence (13). However, this is not an inescapable problem in this kind of bubble model. Instead, it is simply the price we pay for the convenience of a finite state space.

The coincidence in (13) causes the bad seller to pool with the good seller, and slight variations in parameters can break this coincidence. However, if we allow for a continuum of different types of good and bad sellers, then it becomes possible for each type of bad seller to pool with some type of good seller, even if the parameters of the model vary. Details are available upon request. 
This is relevant for bubble bursting policies, since these policies would break the coincidence in (13). However, we do not want the effect of the policy to be driven solely by the lack of robustness of our finite state space model. Thus, we must increase the robustness of the model. However, to keep the modified model as simple as possible, we consider a finite state extension that is only slightly more complicated than the previous model. Specifically, we still assume one type of bad seller, but allow for two types of good seller, a low-confidence type and a high-confidence type.

It then turns out that, in states where the central bank does not actually make an announcement, the presence of a bubble bursting policy rule increases the confidence of bad sellers. We therefore choose parameters such that bad sellers pool with lowconfidence good sellers in the absence of the policy, but with high-confidence good sellers if the policy rule is in place.

\section{B. Basic Setup and Equilibrium}

The previous section examined a policy where the central bank deflates asset prices when some agents know the asset is worthless, even if others do not. However, central banks may know less about fundamentals than all private agents in the economy. For

example, the central bank may only learn that an asset is overpriced in states where all other agents already know this, so the asset is in an Allen et al. (1993) strong bubble.

The policy then becomes one of bursting bubbles. This section shows that such a policy protects bad sellers from each other, so they can more confidently exploit buyers. For consider a bad seller who knows the asset is worthless. She also knows that, if the asset is in a bubble, then the central bank might announce this. Thus, if the central bank makes no announcement, she becomes more confident that she is not in a bubble. That is, she becomes more confident that some other agent does not know the asset is worthless, so she can sell him the asset. She therefore more closely mimics those among the good sellers who are confident that the asset is valuable. This exacerbates 
the lemons problem faced by the more confident of the good sellers, which distorts production decisions. In short, while general deflation of overpriced assets tends to improve production decisions, a bubble bursting policy may hurt production decisions.

This analysis requires a modification of the above bubble model. As explained in the previous subsection, we need to posit two different types of good seller, with two different confidence levels. Bad sellers can then pool with low-confidence good sellers if there is no bubble-bursting policy, and pool with high-confidence good sellers if there is a bubble bursting policy. If bad sellers could not pool with good sellers, asset prices would collapse, and there would be no bubble.

Let the two confidence levels for the good types of seller be $L$, for low confidence, and $H$, for high confidence, and let the states of the world be

$$
\begin{aligned}
\Omega=\left\{b, b_{C B}, e^{B}, f^{B}, e_{1 L}^{G},\right. & e_{2 L}^{G}, e_{3 L}^{G}, f_{1 L}^{G}, f_{2 L}^{G}, f_{3 L}^{G}, \\
& \left.e_{1 H}^{G}, e_{2 H}^{G}, e_{3 H}^{G}, f_{1 H}^{G}, f_{2 H}^{G}, f_{3 H}^{G}\right\} .
\end{aligned}
$$

The asset pays dividend $d(\omega)=d$ in states $\omega=e_{3 L}^{G}, f_{3 L}^{G}, e_{3 H}^{G}$, and $f_{3 H}^{G}$, and zero otherwise. Ellen can produce quantity $a$ of the asset, at cost $c(a)$, in the states $b, b_{C B}$, $e^{B}$, and the $e_{i I}^{G}$ states, $i=1,2,3, I=L, H$, and symmetrically for Frank. Any announcements again occur before production, so central bank announcements, or lack thereof, can influence agents' production decisions.

Suppose that, in the first period, and prior to the central bank announcement, Ellen has four information sets:

$$
\begin{gathered}
E_{\text {Seller }}^{B}=\left\{b, b_{C B}, e^{B}\right\}, E_{\text {Seller }}^{L G}=\left\{e_{1 L}^{G}, e_{2 L}^{G}, e_{3 L}^{G}\right\}, E_{\text {Seller }}^{H G}=\left\{e_{1 H}^{G}, e_{2 H}^{G}, e_{3 H}^{G}\right\} \\
E_{\text {Buyer }}=\left\{f^{B}, f_{1 L}^{G}, f_{2 L}^{G}, f_{3 L}^{G}, f_{1 H}^{G}, f_{2 H}^{G}, f_{3 H}^{G}\right\}
\end{gathered}
$$

and symmetrically for Frank. Here $E_{\text {Seller }}^{B}$ is Ellen's "bad seller" information set, $E_{\text {Seller }}^{L G}$ her "low-confidence good seller" information set, $E_{\text {Seller }}^{H G}$ her "high-confidence 
good seller" information set, and $E_{\text {Buyer }}$ her "buyer" information set. In period 2, the states $b, b_{C B}, e_{1 L}^{G}, e_{1 H}^{G}, f_{1 L}^{G}$, and $f_{1 H}^{G}$ are revealed to all players. In period 3 , all information is revealed and any dividends are paid.

Below, "high confidence" will mean that

$$
\frac{M_{E}\left(e_{2 H}^{G}, e_{3 H}^{G}\right)}{M_{E}\left(e_{1 H}^{G}, e_{2 H}^{G}, e_{3 H}^{G}\right)}>\frac{M_{E}\left(e_{2 L}^{G}, e_{3 L}^{G}\right)}{M_{E}\left(e_{1 L}^{G}, e_{2 L}^{G}, e_{3 L}^{G}\right)} .
$$

This means that, in the first period, high-confidence good sellers attach greater weight to states with positive second period price than do low-confidence good sellers.

As in Section 2, assume symmetry between Ellen and Frank, so $M_{E}(b)=M_{F}(b)$, $M_{E}\left(b_{C B}\right)=M_{F}\left(b_{C B}\right), M_{E}\left(e^{B}\right)=M_{F}\left(f^{B}\right), M_{E}\left(f^{B}\right)=M_{F}\left(e^{B}\right)$, and, for $i=1,2,3$, and $I=L, H, M_{E}\left(e_{i I}^{G}\right)=M_{F}\left(f_{i I}^{G}\right)$, and $M_{E}\left(f_{i I}^{G}\right)=M_{F}\left(e_{i I}^{G}\right)$. We can therefore focus on the states where Ellen can produce and sell:

$$
\Omega_{E}=\left\{b, b_{C B}, e^{B}, e_{1 L}^{G}, e_{2 L}^{G}, e_{3 L}^{G}, e_{1 H}^{G}, e_{2 H}^{G}, e_{3 H}^{G}\right\}
$$

We want the model to have nice equilibria whether or not the central bank announces $b_{C B}$. Specifically, we want a bubble equilibrium to exist where bad sellers pool with some type of good seller, whether or not a bubble-bursting policy rule is in effect. The equilibrium structure that works is presented in Tables 2 and 3. Table 2 presents the structure of equilibrium prices without a bubble bursting policy $(N P)$, and Table 3 presents the structure with a bubble bursting policy $(B P)$.

TABLE 2: EQUILIBRIUM PRICES - NO BUBBLE BURSTING POLICY

\begin{tabular}{|c|c|c|c|c|c|c|c|c|c|c|c|c|c|c|c|c|}
\hline State & $b$ & $b_{C B}$ & $e^{B}$ & $e_{1 L}^{G}$ & $e_{2 L}^{G}$ & $e_{3 L}^{G}$ & $e_{1 H}^{G}$ & $e_{2 H}^{G}$ & $e_{3 H}^{G}$ & $f^{B}$ & $f_{1 L}^{G}$ & $f_{2 L}^{G}$ & $f_{3 L}^{G}$ & $f_{1 H}^{G}$ & $f_{2 H}^{G}$ & $f_{3 H}^{G}$ \\
\hline$t=1$ & $p_{1 L}^{N P}$ & $p_{1 L}^{N P}$ & $p_{1 L}^{N P}$ & $p_{1 L}^{N P}$ & $p_{1 L}^{N P}$ & $p_{1 L}^{N P}$ & $p_{1 H}^{N P}$ & $p_{1 H}^{N P}$ & $p_{1 H}^{N P}$ & $p_{1 L}^{N P}$ & $p_{1 L}^{N P}$ & $p_{1 L}^{N P}$ & $p_{1 L}^{N P}$ & $p_{1 H}^{N P}$ & $p_{1 H}^{N P}$ & $p_{1 H}^{N P}$ \\
$t=2$ & 0 & 0 & $p_{2 L}^{N P}$ & 0 & $p_{2 L}^{N P}$ & $p_{2 L}^{N P}$ & 0 & $p_{2 H}^{N P}$ & $p_{2 H}^{N P}$ & $p_{2 L}^{N P}$ & 0 & $p_{2 L}^{N P}$ & $p_{2 L}^{N P}$ & 0 & $p_{2 H}^{N P}$ & $p_{2 H}^{N P}$ \\
$t=3$ & 0 & 0 & 0 & 0 & 0 & $d$ & 0 & 0 & $d$ & 0 & 0 & 0 & $d$ & 0 & 0 & $d$ \\
\hline
\end{tabular}


TABLE 3: EQUILIBRIUM PRICES - BUBBLE BURSTING POLICY

\begin{tabular}{|c|c|c|c|c|c|c|c|c|c|c|c|c|c|c|c|c|}
\hline State & $b$ & $b_{C B}$ & $e^{B}$ & $e_{1 L}^{G}$ & $e_{2 L}^{G}$ & $e_{3 L}^{G}$ & $e_{1 H}^{G}$ & $e_{2 H}^{G}$ & $e_{3 H}^{G}$ & $f^{B}$ & $f_{1 L}^{G}$ & $f_{2 L}^{G}$ & $f_{3 L}^{G}$ & $f_{1 H}^{G}$ & $f_{2 H}^{G}$ & $f_{3 H}^{G}$ \\
\hline$t=1$ & $p_{1 H}^{B P}$ & 0 & $p_{1 H}^{B P}$ & $p_{1 L}^{B P}$ & $p_{1 L}^{B P}$ & $p_{1 L}^{B P}$ & $p_{1 H}^{B P}$ & $p_{1 H}^{B P}$ & $p_{1 H}^{B P}$ & $p_{1 H}^{B P}$ & $p_{1 L}^{B P}$ & $p_{1 L}^{B P}$ & $p_{1 L}^{B P}$ & $p_{1 H}^{B P}$ & $p_{1 H}^{B P}$ & $p_{1 H}^{B P}$ \\
$t=2$ & 0 & 0 & $p_{2 H}^{B P}$ & 0 & $p_{2 L}^{B P}$ & $p_{2 L}^{B P}$ & 0 & $p_{2 H}^{B P}$ & $p_{2 H}^{B P}$ & $p_{2 H}^{B P}$ & 0 & $p_{2 L}^{B P}$ & $p_{2 L}^{B P}$ & 0 & $p_{2 H}^{B P}$ & $p_{2 H}^{B P}$ \\
$t=3$ & 0 & 0 & 0 & 0 & 0 & $d$ & 0 & 0 & $d$ & 0 & 0 & 0 & $d$ & 0 & 0 & $d$ \\
\hline
\end{tabular}

Note that the main difference between Tables 2 and 3 is in the $b, b_{C B}, e^{B}$, and $f^{B}$ columns. Specifically, bubble bursting reduces the price to zero in state $b_{C B}$, and causes bad sellers, in states $b, e^{B}$, and $f^{B}$, to switch from pooling with low-confidence types (so $p_{t}=p_{t L}^{N P}$ ), to pooling with high-confidence types (so $p_{t}=p_{t H}^{B P}$ ). Note also that, if $p_{1 L}^{N P} \neq p_{1 H}^{N P}$ and $p_{1 L}^{B P} \neq p_{1 H}^{B P}$, then the buyer, by observing $p_{1}(\omega)$, can figure out whether the seller, if good, has high or low confidence, so prices reveal information about seller confidence. The prices themselves, and the conditions for these prices to be an equilibrium, are given in Proposition 5.

PROPOSITION 5: Suppose the following conditions, analogous to conditions (13) through (15) in Proposition 1, are met:

$$
\begin{gathered}
\frac{M_{E}\left(e_{2 L}^{G}, e_{3 L}^{G}\right)}{M_{E}\left(e_{1 L}^{G}, e_{2 L}^{G}, e_{3 L}^{G}\right)}=\frac{M_{E}\left(e^{B}\right)}{M_{E}\left(b, b_{C B}, e^{B}\right)}, \\
\frac{M_{E}\left(e_{2 H}^{G}, e_{3 H}^{G}\right)}{M_{E}\left(e_{1 H}^{G}, e_{2 H}^{G}, e_{3 H}^{G}\right)}=\frac{M_{E}\left(e^{B}\right)}{M_{E}\left(b, e^{B}\right)}, \\
\frac{M_{E}\left(e_{2 I}^{G}, e_{3 I}^{G}\right)}{M_{E}\left(e_{1 I}^{G}, e_{2 I}^{G}, e_{3 I}^{G}\right)} \geq \frac{M_{F}\left(e^{B}, e_{2 I}^{G}, e_{3 I}^{G}\right)}{M_{F}\left(e^{B}, e_{1 I}^{G}, e_{2 I}^{G}, e_{3 I}^{G}\right)},
\end{gathered}
$$

with $I=L, H$, and

$$
\frac{M_{F}\left(e_{3 I}^{G}\right)}{M_{F}\left(e^{B}, e_{2 I}^{G}, e_{3 I}^{G}\right)} \geq \frac{M_{E}\left(e_{3 I}^{G}\right)}{M_{E}\left(e_{2 I}^{G}, e_{3 I}^{G}\right)}
$$

with $I=L, H$. Then, if the central bank does not follow a bubble-bursting policy, an equilibrium exists with prices as in Table 2, where

$$
p_{1 I}^{N P}=\frac{M_{E}\left(e_{2 I}^{G}, e_{3 I}^{G}\right)}{M_{E}\left(e_{1 I}^{G}, e_{2 I}^{G}, e_{3 I}^{G}\right)} p_{2 I}^{N P}, \quad I=L, H
$$




$$
p_{2 L}^{N P}=\frac{M_{F}\left(e_{3 L}^{G}\right) d}{M_{F}\left(e^{B}, e_{2 L}^{G}, e_{3 L}^{G}\right)} \quad \text { and } \quad p_{2 H}^{N P}=\frac{M_{F}\left(e_{3 H}^{G}\right) d}{M_{F}\left(e_{2 H}^{G}, e_{3 H}^{G}\right)}
$$

and where we must also assume that $\left(16^{\prime}\right)$ and $\left(17_{N P}\right)$ yield $p_{1 L}^{N P} \neq p_{1 H}^{N P}$, so prices reveal information about good seller confidence.

If the central bank does follow a bubble bursting policy, then prices are as in Table 3 , with $p_{1 I}^{B P}, I=L, H$, given by $\left(16^{\prime}\right)$, but with $p_{t I}^{N P}$ replaced by $p_{t I}^{B P}$, with

$$
p_{2 L}^{B P}=\frac{M_{F}\left(e_{3 L}^{G}\right) d}{M_{F}\left(e_{2 L}^{G}, e_{3 L}^{G}\right)} \quad \text { and } \quad p_{2 H}^{B P}=\frac{M_{F}\left(e_{3 H}^{G}\right) d}{M_{F}\left(e^{B}, e_{2 H}^{G}, e_{3 H}^{G}\right)}
$$

and where again we assume that $\left(16^{\prime}\right)$ and $\left(17_{B P}\right)$ yield $p_{1 L}^{B P} \neq p_{1 H}^{B P}$.

Finally, Ellen produces $a^{*}\left(p_{1}(\omega)\right)$ (where $a^{*}\left(p_{1}\right)$ satisfies $\left.c^{\prime}\left(a^{*}\left(p_{1}\right)\right)=p_{1}\right)$, in states $\omega=b, b_{C B}, e^{B}$, and the $e_{i I}^{G}$ states, $i=1,2,3, I=L, H$, and symmetrically for Frank, where $p_{1}(\omega)$ is given in Table 2 in the no bubble bursting case, and Table 3 in the bubble bursting case. In period 2, Ellen sells her output to Frank in states $\omega$ where she produced and $p_{2}(\omega)$ is positive, and symmetrically for Frank selling to Ellen.

PROOF: Similar to the proof of Proposition 1.

Proposition 5 says that, given conditions $\left(13_{L}\right),\left(13_{H}\right),\left(14^{\prime}\right)$, and $\left(15^{\prime}\right)$, bad sellers pool with low-confidence good sellers in the absence of a bubble bursting policy, but, in the presence of a bubble-bursting policy, pool with high-confidence good sellers if no announcement is actually made. Thus, bubble bursting policies tend to lead bad sellers to pool with the more confident of the good sellers.

Condition $\left(13_{L}\right)$ is analogous to condition (13) of Proposition 1, except here the bad seller is pooling with the low-confidence good seller when the bad seller thinks the state might be $b_{C B}$. Condition $\left(13_{H}\right)$ is analogous to (13) except that here the bad seller pools with the high-confidence good seller when the bad seller is sure that the state is not $b_{C B}$. Comparing the right hand sides of $\left(13_{L}\right)$ and $\left(13_{H}\right)$ shows that the weight attached to selling in the second period implied by $\left(13_{H}\right)$ is higher than the 
weight implied by $\left(13_{L}\right)$, which is consistent with $(26)$. Thus, $\left(13_{H}\right)$ and $\left(13_{L}\right)$ really do represent confidence levels of high and low-confidence types, respectively.

Condition $\left(14^{\prime}\right)$ is analogous to (14) in Proposition 1. It says that good sellers of each confidence level, $I=L, H$ (and so, bad sellers who pool with them), bid up first period price beyond what the buyers are willing to pay, given that buyers do not know whether sellers are good or bad but can figure out the confidence level of sellers if good (by observing the price). This condition is needed so that the bad sellers, in period 1 , cannot figure out whether they are facing buyers or other bad sellers.

Condition $\left(15^{\prime}\right)$ is analogous to (15) in Proposition 1. It says that the buyer, knowing the confidence level of the seller if good, is willing to pay more than the good seller in period 2, even if the buyer believes that the seller might be bad. This assures that the buyer really does buy from the good seller, even when the bad seller is pooling with the good seller. Of course, it follows from this that the buyer is even more willing to buy from the good seller when he is sure that the seller is not bad.

\section{C. Welfare Analysis: Bursting of Actual Bubbles}

To examine the welfare effects of policy, remember that, since the elasticity of demand is infinite, consumer surplus is zero, so welfare from the market equals expected producer surplus. Also, as before, sellers are indifferent between selling in periods 1 or 2 , so for the purpose of calculating expected welfare, we can imagine that they sell in period 1. Thus, in the absence of a bubble-bursting policy, Ellen's ex ante expected welfare, averaging over all her information sets, is

$$
\Pi\left(p_{1 L}^{N P}\right) M_{E}\left(b, b_{B C}, e^{B}, e_{1 L}^{G}, e_{2 L}^{G}, e_{3 L}^{G}\right)+\Pi\left(p_{1 H}^{N P}\right) M_{E}\left(e_{1 H}^{G}, e_{2 H}^{G}, e_{3 H}^{G}\right)
$$

Similarly, if the central bank follows a bubble-bursting rule, Ellen's welfare will be

$$
\Pi\left(p_{1 L}^{B P}\right) M_{E}\left(e_{1 L}^{G}, e_{2 L}^{G}, e_{3 L}^{G}\right)+\Pi\left(p_{1 H}^{B P}\right) M_{E}\left(b, e^{B}, e_{1 H}^{G}, e_{2 H}^{G}, e_{3 H}^{G}\right)
$$


These are ex ante expected utilities, from Ellen's point of view, before she knows her own type, etc. We can break this up into contributions to expected utility through her bad seller type, her low-confidence good seller type, and her high-confidence good seller type. Proposition 6 treats the welfare contribution through her bad seller type, while Propositions 7 and 8 treat the contributions through her two good seller types.

PROPOSITION 6: In the fixed endowment case, the bubble bursting policy will have no effect on the expected welfare of bad sellers if and only if policy does not affect the actual second period sales price received by bad sellers, so $p_{2 L}^{N P}=p_{2 H}^{B P}$. In this case, the bubble bursting policy helps bad sellers when production is possible.

PROOF: See Appendix C.

Thus, if the transfer effect alone does not hurt bad sellers, then a bubble-bursting policy helps them. This is because the central bank bursts bubbles in states where bad sellers would not be able to sell anyway. The policy therefore does not affect the ex ante probability that bad sellers actually sell their assets. It only gives them some information, before production, about whether they will be able to sell the asset. Thus, if the policy does not affect the actual sale price, its only effect is to allow bad sellers to make better informed production decisions.

We now turn to the effect on high and low-confidence types of good seller. Since the bubble bursting policy causes bad types of seller to pool with high, rather than low-confidence types of good seller, bubble bursting helps low-confidence good sellers, but hurts high-confidence good sellers, as shown in the following Proposition:

PROPOSITION 7: A bubble-bursting policy helps low-confidence types of good seller, but hurts high-confidence types of good seller.

PROOF: Obvious, since $p_{1 L}^{B P}>p_{1 L}^{N P}$ and $p_{1 H}^{B P}<p_{1 H}^{N P}$ (compare $\left(17_{B P}\right)$ to $\left(17_{N P}\right)$ and use $\left.\left(16^{\prime}\right)\right)$. QED

Proposition 7 raises the question of which of the two effects - higher welfare for 
low-confidence good sellers, or lower welfare for high-confidence good sellers - dominates. Of course, if agents put much more weight on their high-confidence types $\left(M_{E}\left(e_{1 H}^{G}, e_{2 H}^{G}, e_{3 H}^{G}\right) \gg M_{E}\left(e_{1 L}^{G}, e_{2 L}^{G}, e_{3 L}^{G}\right)\right)$, then a bubble-bursting policy will hurt good sellers on average, and visa versa. The transfer effect is therefore straightforward.

To focus on production distortions, we choose weights so that the transfer effects on high and low-confidence good sellers perfectly cancel in the fixed endowment case. When we do this, we find that the negative production effects for high-confidence good sellers tend to dominate when production is possible.

PROPOSITION 8: Suppose the shadow prices, $M_{E}(\omega)$ and $M_{F}(\omega)$, are such that, in the fixed endowment case, overall expected welfare of good sellers is unaffected by a bubble bursting policy. Suppose also that the greater confidence of the highconfidence good sellers is sufficient so that

$$
p_{1 H}^{B P}>p_{1 L}^{N P} \text { and } p_{1 H}^{N P}>p_{1 L}^{B P}
$$

Then, in the production case, the negative effect of the bubble bursting policy on highconfidence types dominates the positive effect of the policy on low-confidence types, so the overall expected effect of the bubble bursting policy on good sellers is negative.

PROOF: See Appendix D.

The first half of (30) compares $p_{1}$ for high-confidence good sellers to $p_{1}$ for lowconfidence good sellers, given that, in both cases, the bad seller is pooling with the good seller. Similarly, the second half of (30) compares $p_{1}$ for high-confidence versus low-confidence good sellers, given that the bad seller is not pooling with the good seller. Thus, both halves state that, holding all else equal in the appropriate sense, high-confidence good sellers bid $p_{1}$ up higher than low-confidence good sellers, which makes sense.

Combining Propositions 6 and 8, a bubble bursting policy tends to improve production decisions for bad sellers, but distort production decisions for good sellers, by 
shifting the lemons problem from low to high-confidence good sellers. Intuitively, a bubble is a situation where bad sellers are hurting other bad sellers, and this interferes with their ability to exploit buyers. Thus, a bubble bursting policy, by protecting bad sellers from each other, allows them to more confidently exploit buyers. This exacerbates the lemons problem faced by the more confident of the good sellers. While the overall effect is ambiguous, one can question the value of a policy whose main benefit is to help bad sellers to more efficiently exploit uninformed buyers.

In summary, bubbles tend to exist in environments of asymmetric information. This asymmetric information hurts welfare by creating a lemons problem. However, the most extreme symptom of this asymmetric information - the bubble - does not, itself, necessarily hurt welfare. Thus, curing the symptom may make the underlying problem worse.

\section{WELFARE WITH IRRATIONAL INVESTORS}

The above assumed that all agents were rational. However, the analysis can easily be extended to certain types of irrationality. In particular, while trade in the above model was induced by a hedging motive, it may be more plausible to assume that trade is driven by overconfidence, as in Scheinkman and Xiong (2003). In this case, the shadow prices $M_{E}(\omega)$ and $M_{F}(\omega)$ may differ, not because marginal utilities differ, but because probabilities differ, as in Allen et al. (1993) and Conlon (2004).

However, if agents are irrational, it is not clear how to measure welfare. One could measure welfare according to the policy maker's supposedly true model, yielding what we might call (following De Long et al., 1989, p. 690), a "paternalistic" approach to welfare analysis. Alternatively, one could measure the welfare of each agent according to that agent's own possibly mistaken model (see, e.g., Diamond, 1967, p. 762).

The present paper is more in line with this second approach. Indeed, if shadow prices differ because probability beliefs differ, then Pareto improvements in the present 
framework become Pareto improvements with each agent's welfare evaluated using that agent's own probabilities, rather than any true probabilities. If policy is evaluated from this point of view, then all the above results go through exactly as before.

Of course, if one prefers to measure welfare according to the policy maker's probabilities, then there might be a stronger argument for protecting buyers from bad sellers. On the other hand, if investors are overconfident, then lemons problems may be a good thing, since they may make buyers less confident, and so, may reduce mispricing caused by overconfidence. In any case, one cannot understand the effects of asset deflation policies without tracing the effects of these policies on the lemons problem.

In addition, even if one models overconfident or otherwise irrational agents, there is nevertheless a role for asymmetric information in bubble models. Even overconfident agents may realize that they have something to learn from the opinions of other investors, and this type of information leakage between investors may play a crucial role in market booms and crashes (Doblas-Madrid, 2008, Kai and Conlon, 2008).

\section{CONCLUSION AND POSSIBLE EXTENSIONS}

This paper analyzes bubble-bursting policy in the context of an Allen et al. (1993) greater fool bubble model. This allows us to study greater fool bubbles in a framework with rational agents, which, in turn, allows us to separate the role of policy as responding to distorted incentives from the role of policy as protecting agents from their own irrationality. Of course, the case of agent irrationality is also important.

The main lesson of this study is that, while asymmetric information is bad (since it creates a lemons problem), and asymmetric information tends to create bubbles, bubbles themselves are not necessarily bad. Thus, a policy which reduces the adverse

effects of asymmetric information on uninformed buyers, such as general deflation of overpriced assets, may be a good thing, but a policy which protects bad sellers from each other, such as the bursting of actual bubbles, may be harmful. 
Since this paper provides only a first look at policy in asymmetric information bubble models, it is obviously incomplete in important ways. One obvious extension is to consider what happens if the central bank mistakenly tries to deflate the price of an asset which is not, in fact, overpriced. The effect of the policy then clearly depends on how much investors trust the central bank's judgment (Kai and Conlon, 2008).

Second, it would be useful to incorporate a richer model of the monetary policy instrument, specifically, effects through open market operations. Of course, given the importance of asymmetric information in the present framework, information will be an important part of any transmission mechanism. For example, an interest rate hike may be necessary to credibly signal the Fed's skepticism to the market.

A third extension would be to examine a model with more periods. This would allow us to analyze delayed policy, and the effects of expected future announcements on current resource allocation. For example, in the above framework, any bubbles already exist in the first period, and the central bank either does or does not deflate overpriced assets right away. In contrast, one could imagine a model where, as prices gradually rise, more and more investors come to realize that the asset is overpriced, as in Abreu and Brunnermeier (2003). In this case, early action by the central bank would deflate prices before all agents knew they were overpriced, as in general deflation of overpriced assets, while delayed action would mean the bursting of an actual strong bubble. It would be interesting to see how the above conclusions change when carried over to this more complicated environment.

Finally, future work should vary the information structure, and also modify the assumption that the elasticity of demand for the asset is infinite. In addition, the potential consequences of investor risk aversion should be examined more seriously. 


\section{APPENDIX A: PROOF OF PROPOSITION 1}

Start with period 2. Equation (17) uses Frank's version of (3) to give Frank's willingness to pay for the asset at information set $F_{B u y e r 2}=\left\{e^{B}, e_{C B}^{B}, e_{2}^{G}, e_{3}^{G}\right\}$, given the asset only pays a dividend (of $d$ ) in state $e_{3}^{G}$. Inequality (15) says that Ellen, at her information set $E_{\text {Seller } 2}^{G}=\left\{e_{2}^{G}, e_{3}^{G}\right\}$, values the asset less than Frank at $F_{\text {Buyer } 2 \text {. }}$ Ellen also values the asset less at her other information set $E_{\text {Seller } 2}^{B}=\left\{e^{B}, e_{C B}^{B}\right\}$, since at that information set, Ellen knows that the asset is worthless. Thus, Ellen is willing to sell at the price $p_{2}$ from (17) in the states $e^{B}, e_{C B}^{B}, e_{2}^{G}$, and $e_{3}^{G}$, and Frank bids the price up to exactly that value in those states. By symmetry, the same price applies at states $f^{B}, f_{C B}^{B} f_{2}^{G}$, and $f_{3}^{G}$. At the other states, $b, b_{C B}, e_{1}^{G}$, and $f_{1}^{G}$, it is common knowledge in period 2 that the asset is worthless, so $p_{2}(\omega)$ must be zero in those states.

In period 1 , the price $p_{1}$ from (16) gives Ellen's willingness to pay at her information set $E_{\text {Seller }}^{G}=\left\{e_{1}^{G}, e_{2}^{G}, e_{3}^{G}\right\}$, by (4). Equation (13) says that Ellen has the same willingness to pay at $E_{\text {Seller }}^{B}=\left\{b, b_{C B}, e^{B}, e_{C B}^{B}\right\}$. Meanwhile, (14) says that Frank is willing to pay less than this at his information set $F_{B u y e r}=\left\{e^{B}, e_{C B}^{B}, e_{1}^{G}, e_{2}^{G}, e_{3}^{G}\right\}$ (where he is short sale constrained at zero), while at the information set $F_{\text {Seller }}^{B}=$ $\left\{b, b_{C B}, f^{B}, f_{C B}^{B}\right\}$, Frank is willing to pay exactly $p_{1}$ by symmetry. Thus, at the states $b, b_{C B}, e^{B}, e_{C B}^{B}, e_{1}^{G}, e_{2}^{G}$, and $e_{3}^{G}$, Ellen bids the price up to $p_{1}$ in (16), and Frank is willing to pay less than or equal to this at these states. A similar argument applies to $f^{B}, f_{C B}^{B}, f_{1}^{G}, f_{2}^{G}$, and $f_{3}^{G}$.

Thus, in both periods 1 and 2, the price is bid up to the highest willingness to pay, and the other side is either indifferent to trade or short-sale constrained at the equilibrium trade. Also, each period's price is constant on that period's information sets, so the price reveals no new information. The volume of output and trade also reveal no new information. This therefore yields an equilibrium. QED 


\section{APPENDIX B: PROOF OF PROPOSITION 3}

PROOF: Using $\Pi\left(p_{1}\right)=e p_{1}$ shows that (22) is bigger than (21) when

$$
\frac{M_{E}\left(b, b_{C B}, e^{B}, e_{C B}^{B}, e_{1}^{G}, e_{2}^{G}, e_{3}^{G}\right)}{M_{E}\left(b, e^{B}, e_{1}^{G}, e_{2}^{G}, e_{3}^{G}\right)}<\frac{p_{1}^{D P}}{p_{1}^{N D P}}=\frac{M_{F}\left(e^{B}, e_{C B}^{B}, e_{2}^{G}, e_{3}^{G}\right)}{M_{F}\left(e^{B}, e_{2}^{G}, e_{3}^{G}\right)},
$$

where the last step uses (20). Subtracting one from the left and right hand sides gives

$$
\frac{M_{E}\left(b_{C B}, e_{C B}^{B}\right)}{M_{E}\left(b, e^{B}, e_{1}^{G}, e_{2}^{G}, e_{3}^{G}\right)}<\frac{M_{F}\left(e_{C B}^{B}\right)}{M_{F}\left(e^{B}, e_{2}^{G}, e_{3}^{G}\right)} .
$$

Finally, the left hand side of $(B 1)$ equals the left hand side of $(23)$, since the numerator and denominator both differ by the same factor, $M_{E}\left(e_{C B}^{B}\right) / M_{E}\left(b_{C B}, e_{C B}^{B}\right)=$ $M_{E}\left(e^{B}\right) / M_{E}\left(b, e^{B}\right)($ by $(19))=M_{E}\left(e_{2}^{G}, e_{3}^{G}\right) / M_{E}\left(e_{1}^{G}, e_{2}^{G}, e_{3}^{G}\right)\left(\right.$ by $\left.\left(13^{\prime}\right)\right)$. QED

\section{APPENDIX C: PROOF OF PROPOSITION 6}

The bubble-bursting policy causes the contribution to welfare through the bad types of seller to change from

$$
E U_{B}^{N P}=\Pi\left(p_{1 L}^{N P}\right) M_{E}\left(b, b_{B C}, e^{B}\right) \text { to } E U_{B}^{B P}=\Pi\left(p_{1 H}^{B P}\right) M_{E}\left(b, e^{B}\right) .
$$

In the fixed endowment case, $\Pi\left(p_{1}\right)=e p_{1}$, so $\left(16^{\prime}\right)$ and $\left(13_{L}\right)$ show that $E U_{B}^{N P}=$ e $p_{2 L}^{N P} M_{E}\left(e^{B}\right)$. Similarly, by $\left(16^{\prime}\right)$ and $\left(13_{H}\right), E U_{B}^{B P}=e p_{2 H}^{B P} M_{E}\left(e^{B}\right)$. Thus, $E U_{B}^{N P}$ $=E U_{B}^{B P}$ (so the policy rule does not affect bad sellers' average welfare) if and only if $p_{2 L}^{N P}=p_{2 H}^{B P}$, that is, if and only if bubble policy does not affect bad sellers' $p_{2}$.

Next, if bubble bursting has no effect on bad seller welfare in the fixed endowment case, then $p_{1 L}^{N P} M_{E}\left(b, b_{B C}, e^{B}\right)=p_{1 H}^{B P} M_{E}\left(b, e^{B}\right)$, so

$$
p_{1 H}^{B P} / p_{1 L}^{N P}=M_{E}\left(b, b_{B C}, e^{B}\right) / M_{E}\left(b, e^{B}\right)
$$

This implies that $p_{1 H}^{B P}>p_{1 L}^{N P}$. Thus, since $\Pi\left(p_{1}\right)$ is strictly convex in the produc-

tion case, and $\Pi(0)=0$, it follows that $\Pi\left(p_{1 H}^{B P}\right) / \Pi\left(p_{1 L}^{N P}\right)>p_{1 H}^{B P} / p_{1 L}^{N P}$. This, combined with $(C 2)$, shows that $E U_{B}^{B P}$ is larger than $E U_{B}^{N P}$ in this case. QED 


\section{APPENDIX D: PROOF OF PROPOSITION 8}

Let $A_{L}=M_{E}\left(e_{1 L}^{G}, e_{2 L}^{G}, e_{3 L}^{G}\right)$ and $A_{H}=M_{E}\left(e_{1 H}^{G}, e_{2 H}^{G}, e_{3 H}^{G}\right)$. Then if the overall expected welfare of good sellers is unaffected by a bubble bursting policy in the fixed endowment case, this means that $A_{L} p_{1 L}^{N P}+A_{H} p_{1 H}^{N P}=A_{L} p_{1 L}^{B P}+A_{H} p_{1 H}^{B P}$, so

$$
A_{L}\left[p_{1 L}^{B P}-p_{1 L}^{N P}\right]=A_{H}\left[p_{1 H}^{N P}-p_{1 H}^{B P}\right] .
$$

Let

$$
\delta_{L}=\frac{\Pi\left(p_{1 L}^{B P}\right)-\Pi\left(p_{1 L}^{N P}\right)}{p_{1 L}^{B P}-p_{1 L}^{N P}} \text { and } \delta_{H}=\frac{\Pi\left(p_{1 H}^{N P}\right)-\Pi\left(p_{1 H}^{B P}\right)}{p_{1 H}^{N P}-p_{1 H}^{B P}} .
$$

Since production is possible, $\Pi\left(p_{1}\right)$ is strictly convex. This, combined with $p_{1 L}^{B P}>$ $p_{1 L}^{N P}, p_{1 H}^{N P}>p_{1 H}^{B P}$, and (30) implies that $\delta_{H}>\delta_{L}$. Thus,

$$
\begin{array}{r}
A_{L}\left[\Pi\left(p_{1 L}^{B P}\right)-\Pi\left(p_{1 L}^{N P}\right)\right]=A_{L} \delta_{L}\left[p_{1 L}^{B P}-p_{1 L}^{N P}\right]=A_{H} \delta_{L}\left[p_{1 H}^{N P}-p_{1 H}^{B P}\right] \\
<A_{H} \delta_{H}\left[p_{1 H}^{N P}-p_{1 H}^{B P}\right]=A_{H}\left[\Pi\left(p_{1 H}^{N P}\right)-\Pi\left(p_{1 H}^{B P}\right)\right] .
\end{array}
$$

Here the first step follows from the definition of $\delta_{L}$ and the second step follows from (D1). The third step follows since $p_{1 H}^{N P}-p_{1 H}^{B P}>0$ (by Proposition 7) and $\delta_{L}<\delta_{H}$, and the fourth step uses the definition of $\delta_{H}$. Inequality $(D 3)$ then shows that

$$
A_{L} \Pi\left(p_{1 L}^{B P}\right)+A_{H} \Pi\left(p_{1 H}^{B P}\right)<A_{L} \Pi\left(p_{1 L}^{N P}\right)+A_{H} \Pi\left(p_{1 H}^{N P}\right),
$$

so the bubble bursting policy reduces the overall expected welfare of the good sellers in the production case. QED 


\section{REFERENCES}

Abreu, Dilip and Brunnermeier, Markus K. (2003) "Bubbles and Crashes." Econometrica 71(1) (January), 173-204.

Akerlof, George A. (1970) "The Market for 'Lemons': Quality Uncertainty and the Market Mechanism." Quarterly Journal of Economics 84(3) (August), 488-500.

Allen, Franklin and Gale, Douglas (2000) "Bubbles and Crises." Economic Journal 110(460) (January), 236-55.

Allen, Franklin and Gorton, Gary (1993) "Churning Bubbles." Review of Economic Studies 60(4) (October), 813-36.

Allen, Franklin, Morris, Stephen and Postlewaite, Andrew (1993) "Finite Bubbles with Short Sale Constraints and Asymmetric Information." Journal of Economic Theory 61(2) (December), 206-29.

Allen, Franklin, Morris, Stephen and Shin, Hyun Song (2006) "Beauty Contests, Bubbles and Iterated Expectations in Asset Markets." Review of Financial Studies 19(3) (Fall), 719-52.

Arrow, Kenneth J. (1964) "The Role of Securities in the Optimal Allocation of Risk-bearing." Review of Economic Studies 31(2) (January), 91-96.

Asquith, Paul, Pathak, Parag A., and Ritter, Jay R. (2004) "Short Interest and Stock Returns." NBER Working Paper No. 10434.

Bates, David S. (1991) "The Crash of '87: Was it Expected? The Evidence from Options Markets." Journal of Finance 46(3) (July), 1009-44.

Bean, Charles R. (2004) "Asset Prices, Financial Instability, and Monetary Policy." American Economic Review 94(2) (May), 14-18.

Bernanke, Ben S. and Gertler, Mark (1999) "Monetary Policy and Asset Price Volatility." Federal Reserve Bank of Kansas City Economic Review (Fourth Quarter), $17-51$. 
Bernanke, Ben S. and Gertler, Mark (2001) "Should Central Banks Respond to Movements in Asset Prices?" American Economic Review 91(2) (May), 253-7.

Binmore, Ken (1992) Fun and Games: A Text on Game Theory, Lexington, MA: D. C. Heath and Company.

Blanchard, Olivier, Rhee, Changyong, and Summers, Lawrence (1993) "The Stock Market, Profit, and Investment." Quarterly Journal of Economics 108(1) (February), $115-36$.

Blanchard, Olivier J. and Watson, Mark W. (1982) "Bubbles, Rational Expectations, and Financial Markets," P. Wachtel, ed., Crisis in Economic and Financial Structure, Lexington, MA: Lexington: 295-315.

Bolton, Patrick, Scheinkman, José, and Xiong, Wei (2005) "Executive Compensation and Short-termist Behavior in Speculative Markets." Working paper, Princeton University.

Bordo, Michael D. and Jeanne, Olivier (2002) "Boom-Busts in Asset Prices, Economic Instability, and Monetary Policy." NBER Working Paper No. 8966.

Brunnermeier, Markus K. (2001) Asset Pricing under Asymmetric Information: Bubbles, Crashes, Technical Analysis, and Herding, Oxford, UK: Oxford University Press.

Brunnermeier, Markus K. and Nagel, Stefan (2004) "Hedge Funds and the Technology Bubble." Journal of Finance 59(5) (October), 2013-40.

Buffett, Warren E. (2001) "Letter to Shareholders, Berkshire Hathaway," available at www.berkshirehathaway.com/letters/2000pdf.pdf (February).

Cecchetti, Stephen G., Genberg, Hans, Lipsky, John and Wadhwani, Sushil (2000) Asset Prices and Central Bank Policy, Geneva: International Center for Monetary and Banking Studies.

Cecchetti, Stephen G., Genberg, Hans and Wadhwani, Sushil (2003) "Asset Prices 
in a Flexible Inflation Targeting Framework." W. C. Hunter, G. G. Kaufman, and M. Pomerleano, ed., Asset Price Bubbles: The Implications for Monetary, Regulatory, and International Policies, Cambridge, MA: MIT Press: 427-44.

Chancellor, Edward (2000) Devil Take the Hindmost: A History of Financial Speculation, New York, NY: Penguin.

Chirinko, Robert S. and Schaller, Huntley (2001) "Business Fixed Investment and 'Bubbles': The Japanese Case." American Economic Review 91(3) (June), 663-80.

Conlon, John R. (2004) "Simple Finite Horizon Bubbles Robust to Higher Order Knowledge." Econometrica 72(3) (May), 927-36.

De Long, J. Bradford, Shleifer, Andrei, Summers, Lawrence H. and Waldmann, Robert J. (1989) "The Size and Incidence of the Losses from Noise Trading." Journal of Finance 44(3) (July), 681-696.

Dhar, Ravi, and Goetzmann, William N. (2005) "Bubble Investors: What Were They Thinking?" Yale ICF Working Paper No. 05-01.

Diamond, Peter A. (1967) "The Role of a Stock Market in a General Equilibrium Model with Technological Uncertainty." American Economic Review 57(4) (September), 759-776.

Doblas-Madrid, Antonio (2008) "A Robust Model of Bubbles with Multidimensional Uncertainty." working paper, Michigan State University.

Dupor, Bill (2005) "Stabilizing Non-fundamental Asset Price Movements under Discretion and Limited Information." Journal of Monetary Economics 52(4) (May), 727-747.

The Economist (1998) "America's Bubble Economy." 346(8064) (April), 15-16.

The Economist (2007) "Tangled Reins." 384(8545) (September), 92.

Federal Open Market Committee, Transcripts, various dates.

Friedman, Milton and Anna J. Schwartz (1963) A Monetary History of the United 
States, 1867-1960, Princeton, NJ: Princeton University Press.

Gai, Prasanna, Lester, Benjamin, and Millard, Stephen (2004) "Asset Prices, Financial Imbalances, and Central Bank Policy." Working paper, Bank of England.

Garber, Peter M. (2000) Famous First Bubbles, Cambridge, MA: MIT Press.

Gilchrist, Simon, Himmelberg, Charles P. and Huberman, Gur (2004) "Do Stock Price Bubbles Influence Corporate Investment?" Journal of Monetary Economics 52(4) (May), 805-827.

Harrison, J. Michael and Kreps, David M. (1978) "Speculative Investor Behavior in a Stock Market with Heterogeneous Expectations." Quarterly Journal of Economics 92(2) (May), 323-336.

Harrison, J. Michael and Kreps, David M. (1979) "Martingales and Arbitrage in Multiperiod Securities Markets." Journal of Economic Theory 20(3) (June), 381-408.

Higgins, Matthew and Osler, Carol (1997) "Asset Market Hangovers and Economic Growth: the OECD During 1984-93." Oxford Review of Economic Policy 13(3) (Autumn), 110-134.

Hirshleifer, Jack (1971) "The Private and Social Value of Information and the Reward to Inventive Activity." American Economic Review 61(4) (September), 561-74.

Huang, Chi-fu and Litzenberger, Robert H. (1988) Foundations for Financial Economics, Englewood Cliffs, NJ: Prentice Hall.

Hunter, William C., Kaufman, George G. and Pomerleano, Michael, eds. (2003) Asset Price Bubbles: The Implications for Monetary, Regulatory, and International Policies, Cambridge, MA: MIT Press.

Ingves, Stefan (2007) "Housing and Monetary Policy: A View from an InflationTargeting Central Bank." In Housing, Housing Finance, and Monetary Policy: A Symposium Sponsored by the Federal Reserve Bank of Kansas City, 433-443.

Jones, Charles M. and Lamont, Owen A. (2002) "Short Sale Constraints and Stock 
Returns." Journal of Financial Economics 66(2-3) (November), 207-39.

Kai, Guo, and John Conlon (2008) "Why Bubble-Bursting is Unpredictable: Welfare Effects of Anti-bubble Policy when Central Banks Make Mistakes," working paper, University of Mississippi.

Kent, Christopher and Lowe, Philip (1997) "Asset-Price Bubbles and Monetary Policy." Reserve Bank of Australia, Research Discussion Paper No. 9709.

Kindleberger, Charles P. (2000) Manias, Panics, and Crashes: A History of Financial Crises, Third Edition, New York, NY: Wiley.

LeRoy, Stephen F. (2004) "Rational Exuberance." Journal of Economic Literature 42(3) (September), 783-804.

Milgrom, Paul and Stokey, Nancy (1982) "Information, Trade and Common Knowledge." Journal of Economic Theory 26(1) (February), 17-27.

Miller, Edward M. (1977) "Risk, Uncertainty, and Divergence of Opinion." Journal of Finance 32(3) (June), 1151-1168.

Mishkin, Frederic S. (2007) "Housing and the Monetary Transmission Mechanism." In Housing, Housing Finance, and Monetary Policy: A Symposium Sponsored by the Federal Reserve Bank of Kansas City, 359-413.

Morris, Stephen, Postlewaite, Andrew and Shin, Hyun Song (1995) "Depth of Knowledge and the Effect of Higher Order Uncertainty." Economic Theory 6(3) (October), 453-67.

Ofek, Eli and Richardson, Matthew (2003) "Dot Com Mania: The Rise and Fall of Internet Stock Prices." Journal of Finance 58(3) (June), 1113-37.

Panageas, Stavros (2003) "Speculation, Overpricing, and Investment - Theory and Empirical Evidence." Working paper, MIT.

Rappoport, Peter and White, Eugene N. (1993) "Was There a Bubble in the 1929 Stock Market?" Journal of Economic History 53(3) (September), 549-74. 
Rappoport, Peter and White, Eugene N. (1994) "Was the Crash of 1929 Expected? American Economic Review 84(1) (March), 271-81.

Samuelson, Larry (2004) "Modeling Knowledge in Economic Analysis." Journal of Economic Literature 42(2) (June), 367-403.

Samuelson, Paul A. (1958) "An Exact Consumption-Loan Model of Interest with or without the Social Contrivance of Money." Journal of Political Economy 66(6) (December), 467-82.

Santos, Manuel S. and Woodford, Michael (1997) "Rational Asset Pricing Bubbles," Econometrica 65(1) (January), 19-57.

Scheinkman, Jose and Xiong, Wei (2003) "Overconfidence and Speculative Bubbles." Journal of Political Economy 111(6) (December), 1183-219.

Schlesinger, Jacob M. (1999) "Fed 'Bubble' Policy: Watch, Don't Pop." Wall Street Journal (August 30).

Shiller, Robert J. (2000) Irrational Exuberance, New York, NY: Broadway Books.

Shiller, Robert J. (2007) "Understanding Recent Trends in House Prices and Homeownership." In Housing, Housing Finance, and Monetary Policy: A Symposium Sponsored by the Federal Reserve Bank of Kansas City, 89-123.

Temin, Peter and Voth, Hans-Joachim (2004) "Riding the South Sea Bubble." American Economic Review 94(5) (December), 1654-68.

Tirole, Jean (1982) "On the Possibility of Speculation under Rational Expectations." Econometrica 50(5) (September), 1163-80.

Tirole, Jean (1985) "Asset Bubbles and Overlapping Generations." Econometrica 53(5) (September), 1499-528. 